Emilio Bouza'

José Ramón Arribas ${ }^{2}$

Belén Alejos ${ }^{3}$

José Ignacio Bernardino ${ }^{4}$

Maye Coiras ${ }^{5}$

Pep Coll ${ }^{6}$

Jorge Del Romero ${ }^{7}$

María José Fuster ${ }^{8}$

Miguel Górgolas ${ }^{9}$

Alipio Gutiérrez ${ }^{10}$

Diego Gracia ${ }^{11}$

Victoria Hernando ${ }^{12}$

Javier Martínez-Picado ${ }^{13}$

José Manuel Martínez

Sesmero ${ }^{14}$

Esteban Martínez ${ }^{15}$

Santiago Moreno ${ }^{16}$

Beatriz Mothe ${ }^{17}$

Maria Luisa Navarro ${ }^{18}$

Daniel Podzamczer ${ }^{19}$

Federico Pulido ${ }^{20}$

José Tomás Ramos ${ }^{21}$

Ezequiel Ruiz-Mateos ${ }^{22}$

Inés Suárez Garciá23

Esteban Palomo ${ }^{24}$

\title{
Past and future of HIV infection. A document based on expert opinion
}

\author{
${ }^{1}$ Clinical Microbiology and Infectious Diseases Department, Hospital General Universitario Gregorio Marañón, De- \\ partment of Medicine, Universidad Complutense de Madrid (UCM), Instituto de Investigación Sanitaria Gregorio Mara- \\ ñón, and CIBER de Enfermedades Respiratorias (CIBERES CB06/06/0058), Madrid. \\ ${ }^{2}$ Director of HIV and Infectious Diseases Research, Hospital La Paz. Madrid. Associate Professor at the Universidad Autó- \\ noma de Madrid. \\ ${ }^{3}$ Researcher at the Instituto de Salud Carlos III. Madrid \\ ${ }^{4}$ HIV Unit. Internal Medicine Department. La Paz Hospital \\ ${ }^{5}$ AIDS Immunopathology Unit. National Microbiology Centre. Carlos III Healthcare Institute, Madrid. \\ ${ }^{6}$ IrsiCaixa-Institut de Recerca de la Sida. HIV Unit. Germans Trias i Pujol Hospital. Badalona. BCN Checkpoint. Barcelona. \\ ${ }^{7}$ Director of the Sandoval Health Centre. IdISSC. San Carlos Clinical Hospital. Madrid \\ ${ }^{8}$ Executive Director of the Spanish Interdisciplinary AIDS Society (SEISIDA) and Professor at the UNED. Madrid. \\ ${ }^{9}$ Associate Head of Infectious Diseases. Jiménez Diaz Foundation. Madrid \\ ${ }^{10} \mathrm{Head}$ of Health Content at RTVM and 1st vice-president of the ANIS National Association of Health Informers. Madrid. \\ ${ }^{11}$ President of the Health Sciences Foundation. Madrid \\ ${ }^{12}$ National Epidemiology Centre-Carlos III Health Institute. Madrid \\ ${ }^{13}$ Research Professor at the Catalan Institute for Research and Advanced Studies (ICREA) at IrsiCaixa and Associate Pro- \\ fessor at the University of Vic (UVic). \\ ${ }^{14}$ Head of the Pharmacy Department, San Carlos Clinical Hospital, Madrid. \\ ${ }^{15}$ Senior Consultant, Infection Service, Clinical Hospital, Barcelona \\ ${ }^{16}$ Department of Infectious Diseases, Ramón y Cajal University Hospital, Department of Medicine and Medical Speciali- \\ ties, University of Alcalá (UAH), Ramón y Cajal Institute of Health Research, and AIDS Research Network, Madrid. \\ ${ }^{17}$ IrsiCaixa - Institut de Recerca de la Sida, Infectious Diseases Service, Hospital Germans Trias i Pujol, Badalona. \\ ${ }^{18}$ Group Infections in the Paediatric Population. Paediatric Infectious Diseases Section. Gregorio Marañón General Uni- \\ versity Hospital. Madrid. \\ ${ }^{19}$ HIV and STI Unit, Infectious Diseases Department. Hospital Universitari de Bellvitge. Barcelona. \\ ${ }^{20}$ Assistant Doctor at the HIV Unit of the Hospital Universitario 12 October, imas12, Madrid. Associate Professor at the \\ Complutense University of Madrid. \\ ${ }^{21}$ Head of the Paediatrics Department, UCM Professor of Paediatrics. San Carlos Clinical Hospital, Madrid. \\ ${ }^{22}$ Clinical Unit for Infectious Diseases Virgen del Rocío University Hospital / Seville Institute de Biomedicine. Seville. / \\ $\mathrm{CSIC/} \mathrm{Seville} \mathrm{University.}$ \\ ${ }^{23}$ Infanta Sofía University Hospital, Madrid. Universidad Europea, Madrid. \\ ${ }^{24}$ Doctor in Pharmacy. Health Sciences Foundation Director. Madrid.
}

Article history

Received:16 June 2021; Accepted: 2 September 2021; Published: 12 January 2021

\section{ABSTRACT}

HIV infection is now almost 40 years old. In this time, along with the catastrophe and tragedy that it has entailed, it has also represented the capacity of modern society to take on a challenge of this magnitude and to transform an almost uniformly lethal disease into a chronic illness, compatible with a practically normal personal and relationship life. This anniversary seemed an ideal moment to pause and reflect on the future of HIV infection, the challenges that remain to be addressed and the prospects for the immediate future. This reflection has to go beyond merely technical approaches, by specialized profes-

Correspondence:

Emilio Bouza MD, PhD

Gregorio Marañón Health Research Institute.

C/ Dr. Esquerdo, 46

28007 Madrid, Spain

E-mail:emilio.bouza@gmail.com sionals, to also address social and ethical aspects. For this reason, the Health Sciences Foundation convened a group of experts in different aspects of this disease to discuss a series of questions that seemed pertinent to all those present. Each question was presented by one of the participants and discussed by the group. The document we offer is the result of this reflection.

Keywords: HIV infection, AIDS, chronic disease, history, prevention, epidemiology, eradication, vaccine, two-drug treatment, immunotherapy.

Pasado y futuro de la infección por VIH. Un documento basado en la opinión de expertos

\section{RESUMEN}

La infección por VIH cumple ahora casi 40 años de existencia. En este tiempo, junto a la catástrofe y la tragedia que ha supuesto, ha representado también la capacidad de la sociedad 
moderna de asumir un reto de esta magnitud y de transformar, gracias al tratamiento antirretroviral, una enfermedad mayoritariamente letal en una enfermedad crónica, compatible con una vida personal y de relación prácticamente normales. Este aniversario parecia un momento idóneo para pararse a reflexionar sobre el futuro de la infección VIH, los retos que todavía quedan por abordar y las perspectivas para el inmediato futuro. Esa reflexión tiene que ir más allá de planteamientos meramente técnicos, de profesionales especializados, para abordar aspectos sociales y éticos. Por este motivo, la Fundación de Ciencias de la Salud convocó a un grupo de expertos en distintos aspectos de esta infección para discutir una serie de preguntas que parecieron pertinentes a todos los convocados. Cada pregunta era expuesta por uno de los participantes y discutida por el grupo. El documento que ofrecemos es el resultado de esa reflexión.

Palabras clave: Infección VIH, SIDA, enfermedad crónica, historia, prevención, epidemiología, erradicación, vacuna, tratamiento con dos fármacos, inmunoterapia

\section{INTRODUCTION}

The AIDS epidemic is now 40 years old. While it is one of humanity's greatest tragedies, it is at the same time one of its greatest successes in scientific development and research. What was achieved was unimaginable 4 decades ago: to turn a profoundly immunosuppressive disease into a chronic infection where a latent virus allows, under very tolerable medication, a state almost close to normality. The research effort has been enormous, but the results are extraordinary.

On the other hand, the failure to eradicate the disease, the failure to produce a vaccine and the problems of social injustice that still persist around HIV infection still leave room for improvement.

It therefore seems appropriate to undertake a process of reflection on where we are after almost four decades and where we want to be in the not-too-distant future. This reflection can only be complete if it is carried out from a multidisciplinary perspective that includes the points of view of the different actors involved in the problem.

For this reason, the Health Sciences Foundation convened a large group of people from different backgrounds to try to provide answers to a series of questions that society is asking about the past and future of HIV infection. The questions posed were accepted by the group as relevant and assigned to a speaker who presented his or her point of view and data for discussion with the group.

We now turn to the questions, the rationale underpinning the answer and the conclusions on each point.

\section{AS WE APPROACH THE 4OTH ANNIVERSARY OF THE BEGINNING OF THE HIV EPIDEMIC, WHAT MAJOR HISTORICAL MILESTONES WOULD YOU HIGHLIGHT?}

\section{Daniel Podzamczer}

There are probably many milestones in the history of HIV infection since its discovery, but I would highlight the following 12:

1. On June 5 th, 1981 , the $C D C$ alerted of the occurrence of 5 cases of Pneumocystis carinii (now P. jirovecii) pneumonia in previously healthy homosexual men, associated with CMV disease or infection and suggesting that it was due to an immunodeficiency whose cause was not yet known [1-4].

2. In 1984, French researchers on the one hand and US researchers on the other - with controversy over the claim to first discovery - isolated a virus they called HTLVIII (US) or LAV (France), later unified as HIV, as the cause of the socalled acquired immunodeficiency syndrome (AIDS). This landmark finding made it possible,months later, to detect the presence of antibodies to the virus through serological tests that were immediately widely used to diagnose HIV infection in people who had contracted the virus [5-13].

3. In the 1980s, the knowledge that famous personalities from the world of art and sport (Rock Hudson, Freddy Mercury, Magic Johnson, etc.) had been infected with HIV was important in drawing attention to a growing pandemic and demonstrating that it did not only affect marginalised groups in society [14].

4. In 1987, the first antiretroviral drug, AZT (azidothymidine or zidovudine), was marketed in Spain, with the capacity to partially and temporarily inhibit HIV replication, demonstrating in a randomised, double-blind clinical trial that patients receiving this treatment had a significantly longer survival (although the difference was only months). AZT also had considerable toxicity, but it was the first therapeutic step in the fight against HIV $[14,15]$.

5. In 1994, study 076 was the first to demonstrate that effective antiretroviral treatment (ART) was able to prevent vertical transmission of HIV in pregnant women. This randomised, double-blind clinical trial showed a 76\% reduction of infection in newborns of women taking AZT during pregnancy versus placebo[16].

6. In 1996, coinciding with the International AIDS Conference in Vancouver, it was shown that a three-drug regimen of ART - two nucleoside analogues and a protease inhibitor - was able to persistently inhibit HIV replication and at least partially restore immunity as assessed by CD4 count and CD4/CD8 ratio [17].

7. That same year, we were able to start assessing the response to ART in our hospital laboratories by measuring plasma viral load, which allowed us to know within a few weeks whether or not the treatment was being effective[18]. In 2005, the first scientific evidence of the preventive efficacy of suppressive ART on sexual transmission of HIV in serodiscordant heterosexual couples was presented [19].

8. In 2007, the first triple-ART regimen (TDF/FTC/EFV) was marketed in Spain in a single tablet to be administered once a day [20]. It was the beginning of a phase that was 
followed in the next decade by the marketing of several one-pill-a-day formulations of effective, well-tolerated and easy-to-take drugs, some of them based on a high genetic barrier integrase inhibitor; drugs now considered preferred drugs for ART initiation [21]. This has contributed significantly to transforming HIV infection into a chronic disease with a survival similar to the general population in patients who start ART early in the course of infection - and with an excellent quality of life. The first long-term ART with an INI - Cabotegravir - and an NNRTI - Rilpivirine - will soon be marketed, allowing patients who are considered good candidates to receive intramuscular injections every 2 months instead of taking daily pills, which may have benefits on adherence, quality of life and stigma for HIV-infected people [22].

9. In 2009, the first data were released on the so-called "Berlin patient", the first HIV-infected adult to be assumed to have been cleared of the virus - and therefore cured - following a bone marrow transplant for treatment of leukaemia refractory to chemotherapy and radiotherapy. This transplant was from a donor with the delta 32 mutation of the CCR5 co-receptor of CD4 cells, which has long been known to confer immunity of CD4 cells to HIV, which is unable to infect them [23].

10. In 2011, the HPTN052 study showed that early ART initiation in serodiscordant couples reduced HIV transmission by 96\%. These data were key to the widespread recommendation for early initiation of ART regardless of CD4 count [24].

11. In 2012, the FDA approved pre-exposure prophylaxis (PrEP), the administration of a daily TDF/FTC regimen to patients at high risk of HIV infection due to sexual practices. This approval was based on several international clinical trials of thousands of participants - men who have sex with men, women and heterosexual men - which showed that such treatment was able to reduce the proportion of people acquiring sexually transmitted infections by $40-86 \%$, depending on the study, provided adherence was acceptable. The preventive benefits of PrEP, which has been shown to be cost-effective, were seen in the following years in the significant decrease in the incidence of new HIV infections in cities or countries where its use was authorised [25]. In November 2019, PrEP was approved and included in the National Health System's service portfolio.

12. Data from the PARTNER 1 and 2 studies demonstrating the absence of sexual transmission of HIV from ART-infected individuals with undetectable plasma viral loads were published in 2016 and 2019. Undoubtedly these important data (summarised in the $\mathrm{I}=\mathrm{I}$ expression (undetectable $=$ untransmissible; undetectable=untransmittable", or " $\mathrm{U}=\mathrm{U}$ ") can contribute to reducing the stigma and psychological problems associated with HIV infection [25-27].

\section{Conclusion:}

After $\mathbf{4 0}$ years, HIV infection has changed from being a fatal disease, in the vast majority of cases, to a chronic infection, with an excellent quality of life for people on antiretroviral treatment (ART). New prevention measures, the efficacy of current ART and the absence of transmission in virologically suppressed individuals will help to reduce the incidence of infection, as well as its social stigma, pending a cure

\section{WHAT IS THE CURRENT SITUATION OF THE EPIDEMIC IN FIGURES?}

\section{Belén Alejos}

According to the latest UNAIDS report, 37.9 million people were living with HIV infection globally in 2018. Of them, $79 \%$ of people living with HIV knew their HIV status (i.e. about 8.1 million people did not know they were living with HIV). In terms of access to antiretroviral treatment, 23.3 million people had access to antiretroviral therapy, up from 7.7 million in 2010. Consequently, there has been a steady decline from the number of new infections to 1.7 million new HIV infections in 2018 [28].

In the WHO European Region, which includes Europe and Central Asia, 159,420 new diagnoses were recorded in 2017, corresponding to a rate of 20.0 new diagnoses per 100,000 people. As has been observed over the last decade, most of these cases were recorded in the eastern region (82\%), followed by the western region (14\%) and the central region (4\%). The current HIV epidemic varies greatly by geographical area. Epidemics in the central and eastern regions account for the majority of cases, and the most frequent mode of transmission is heterosexual practices followed by injection drug use. In contrast, in the western part of Europe, sex between men was the most common mode of transmission [27]. Overall, the rate of new HIV diagnoses increased by 37\% from 2008 to 2017 across the WHO European Region, but there are also different patterns by geographical area. While a $27 \%$ decrease in the rate of new diagnoses is observed in the western region, rates continue to increase in the eastern and central regions (68\% and $121 \%$ respectively). In addition, diagnostic delay remains very high in all regions and more than half of new diagnoses were late presenters (CD $4<350$ cells/ $/ \mu \mathrm{L}$ ).

In Spain, it is estimated that there are currently between 140,000 and 170,000 people living with HIV, which represents a prevalence of $0.4 \%$. According to data from the epidemiological surveillance report on HIV/AIDS in Spain, 3,381 new HIV diagnoses were recorded in 2017, giving a rate of 8.82 cases per 100,000 inhabitants after correcting for delayed reporting [29]. This rate is similar to other countries in the WHO European region, but higher than the average for EU and Western European countries. In comparison with the countries of the European Union/European Economic Area (EU/EEA), we observe in Spain a higher percentage of diagnoses in men (84.6\% versus $75.1 \%$ ) and a lower percentage in people over 50 years of age (14.8\% versus 19.3\%). The most frequent mode of transmission is men who have sex with men (54.3\%), followed by heterosexual (28.2\%) and injection drug users (3.1\%) [30].

The time trend in the rate of new diagnoses in Spain in 
the period 2009-2017 is downward, however different patterns are observed depending on the mode of transmission. In the groups of injection drug users and heterosexual practices, a steady decline is observed throughout the period for both males and females. Whilst in the group of men who have sex with men a downward trend is observed only from 2015 onwards, although disaggregated by origin this decrease is only observed in Spanish MSM. Although late diagnosis has decreased slightly since 2009, it is still very high; in 2017 47.8\% of HIV diagnoses were made late (CD 4350 cells $/ \mu \mathrm{L}$ ).

The 90-90-90 targets set by UNAIDS are that by 2020 at least $90 \%$ of people living with HIV should be diagnosed; at least $90 \%$ of diagnosed people should be on antiretroviral treatment; and at least $90 \%$ of people on antiretroviral treatment should have an undetectable viral load. Overall, this would mean that at least $73 \%$ of people living with HIV have an undetectable viral load. Modelling suggests that achieving these targets by 2020 would mean ending the epidemic by 2030.

The Spanish figures on the 90-90-90 strategy have been provided by the HIV and Risk Behaviour Surveillance Unit [31]. Of the 146,500 people living with HIV in Spain, 86.2\% knew their HIV diagnosis, 93.4\% were receiving antiretroviral treatment, and of those on treatment, 90.4\% had reached an undetectable viral load. Although we are above the EU/ EEA average and very close to achieving the targets set by UNAIDS for 2020, there are still approximately $13.7 \%$ of people living with HIV in Spain who do not know they have the infection.

\section{Conclusion:}

HIV remains a priority for European Public Health. However, we have effective tools such as universal prevention, screening and treatment to address the fight against the HIV epidemic. It is therefore essential that these tools be implemented more widely and adapted to the time and characteristics of the epidemic.

\section{IS HIV ERADICATION POSSIBLE? FOR WHAT YEAR?}

\section{Victoria Hernando}

In 2014, the United Nations Programme on HIV and AIDS (UNAIDS) set the 90-90-90 target for the year 2020, so that $90 \%$ of people living with HIV would know their diagnosis, 90\% of them would receive antiretroviral treatment and $90 \%$ of people on treatment would have a suppressed viral load, aiming for the end of the AIDS epidemic by 2030 [32]. These targets are monitored through the "treatment cascade" or "continuum of care" that allows the HIV epidemic situation in a particular country or geographic area to be assessed. In Spain, in 2016, the percentages of each of these targets would be: $86.2 \%, 93.4 \%$ and $90.4 \%$, so we would be very close to reaching the targets set by UNAIDS [32].

Various mathematical models have estimated that if the 90-90-90 targets proposed by UNAIDS were achieved globally, increasing levels of diagnosis and antiretroviral treat- ment coverage could achieve an approximate 40\% reduction in annual HIV incidence globally [33]. However, it should be borne in mind that in countries such as Spain, where access to treatment is universal and the fraction undiagnosed is low, the improvement that would be achieved in reaching the UNAIDS targets on incidence reduction would not be as great as in other countries where the prevalence of HIV infection is higher [34].

To the question posed here, "Is it possible to eradicate HIV?", the answer from a public health point of view is clearly, no. When we talk about HIV eradication, we can find a clinical concept, which would be the cure of the individual, i.e. the complete eradication of the virus from a patient's body. On the other hand, eradication, as an epidemiological or public health concept, at the population level, is defined as the complete elimination of the disease-causing agent from the natural environment (not from controlled laboratories). In any case, HIV eradication is not a goal that we can set as achievable in a short period of time. In the case of complete cure of the individual, we know that even with the highly effective antiretroviral therapy available to us, and even if the subject has an undetectable viral load, there remains a low level of viral replication and cellular reservoirs that contribute to HIV persistence and make HIV infection a chronic disease [33]. To achieve eradication at the population level, curative treatment and preventive vaccines should be available and affordable for the entire world population.

We can, however, speak of elimination and control in some areas with regard to HIV infection. Disease elimination refers to the complete cessation of the incidence of cases in a given geographical area or population subgroup. For HIV infection this has been achieved for blood transfusion-associated transmission and mother-to-child transmission[35]. But unlike eradication, in the case of elimination, as the causative agent is still present in the natural environment, we must maintain the preventive and intervention measures that led to the elimination of the disease.

The primary prevention measures that allowed us to reach this level have been HIV testing of all blood donors and monitoring of pregnant women - HIV testing during pregnancy, antiretroviral treatment of pregnant HIV-infected women and newborns, and formula feeding of newborns. While there may still be cases of vertical transmission of HIV, these cases must be examined to identify where prevention systems and policies have failed to ensure universal access to prevention methods.

There are other primary prevention measures (aimed at preventing the onset of infection) that can be taken depending on the environment in which we find ourselves [33], harm reduction programmes for injecting drug users (syringe exchange, supervised consumption rooms, methadone treatment) [36], PrEP [36-38] and male circumcision in certain contexts[39]. All these measures that we can apply to reduce sexual transmission of the virus and the acquisition of infection through injection drug use are aimed at infection control, i.e. reducing the incidence, prevalence or mortality of cases in a 


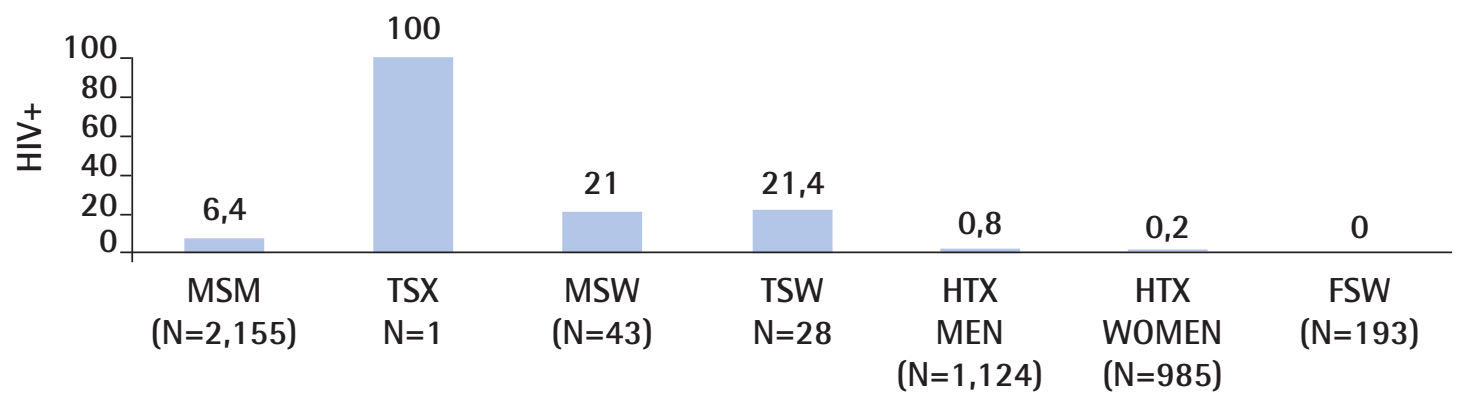

Figure 1 Sandoval Centre 2018. HIV seroprevalence at first visit, by exposure category. $\mathrm{N}=4,529$ people (1st consultation).

MSM: Men who have sex with men; TSX: Transgender people; MSW: Male sex workers, TSW: Transgender sex workers; HTX: Heterosexual; FSW: Female sex workers

given geographical area. The elimination of sexual transmission of HIV, i.e. zero incidence, cannot be considered a realistic goal, as the number of cases through this mode of transmission remains very high.

In addition, we can highlight other key aspects of monitoring the HIV epidemic that help control infection and improve the situation of people living with HIV infection. These would be secondary prevention measures such as early diagnosis and rapid access to antiretroviral treatment. Increase the frequency of HIV testing, especially for people at high risk of acquiring HIV infection, such as men who have sex with men (MSM) and people who inject drugs [40]. In recent years, HIV testing sites have diversified to include not only health care settings, but also community settings, and there is a need to promote rapid, safe and confidential access, as there is still a high burden of discrimination and stigmatisation of people with HIV infection. According to Public Health England (PHE) officials, this has been one of the key points in the decline in the numbers of new HIV diagnoses in recent years in England $[41,42]$.

Similarly, early initiation of antiretroviral therapy not only slows disease progression in the HIV-infected person, but also helps control the onset of other co-morbidities associated with both HIV infection and the longer life expectancy of HIV-infected people. It also interrupts transmission of the virus, as a person who achieves and maintains an undetectable viral load does not transmit HIV to sexual partners [43]. High adherence to prescribed antiretroviral treatment is vital to maintain the effectiveness of this preventive measure.

\section{Conclusion:}

We cannot currently consider the eradication of HIV as an achievable goal in the near future, but we can reduce to zero the incidence of cases in certain modes of transmission and improve control in others, such as sexual transmission.

\section{WHAT IS A PERSON AT RISK? HOW IS IT DEFINED?}

\section{Jorge del Romero}

The epidemiology of HIV in the world is highly variable in each geographic region.

In Europe, HIV prevalence is $0.4 \%$, while in Africa it is around 4\% (WHO, 2018) [44]. According to WHO, the following are generally considered "specific populations" for STIs/HIV:

- Sex workers and their clients

- Men who have sex with men (MSM)

- Transgender people (TSX)

- Prison inmates

- Youths and adolescents

- Drug users

A study conducted at an STI clinic in Madrid in 2016 [45] concluded that those most at risk of HIV infection were: MSM between 20 and 39 years old, with several previous negative serologies, a history of STIs and multiple sexual partners with whom they had sex without condoms, under the effect of recreational drugs (chemsex) [46].

The highest prevalences of HIV infection observed among the 4,529 people seen for first consultations at the Sandoval Centre in 2018 were among transgender men and women in sex work (MSW, FSW) and men who have sex with men (MSM) (Figure 1)

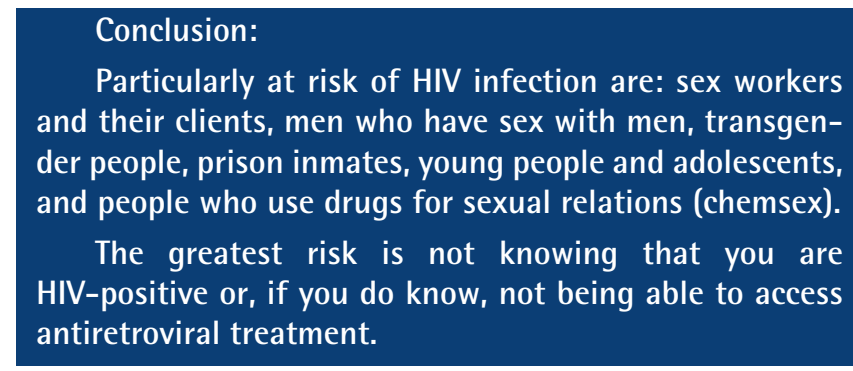




\section{WHAT IS LIFE LIKE FOR AN HIV-POSITIVE PATIENT IN PHYSICAL TERMS?}

\section{Maria José Fuster}

Overall, it can be stated that the clinical situation of people living with HIV (PLHIV) has evolved positively with the expansion of antiretroviral treatment and there is a continuing trend towards improvement in key clinical immunological and virological parameters [47]. However, there are different profiles of PLHIV and different levels of complexity in their health care needs. The challenges faced by older PLHIV with co-morbidities are not the same as those faced by controlled and stable patients, those who are newly diagnosed, those with problematic substance use, or those who are socially excluded, to give an example of different profiles. Therefore, the life of PLHIV in all its facets is not homogeneous but there is a lot of variability.

Recent research by the Spanish Interdisciplinary AIDS Society (SEISIDA) measuring quality of life in a large sample of PLHIV in Spain $(n=1,441)$ showed that the overall health perception and quality of life score was close to 70 on a scale of $100(68.5 \pm 22.61)$. Health perception was lower in certain well-established PLHIV profiles, such as people over 50, women, or those with a lower socio-educational level[48]. The overall perception of health is influenced by many factors, one of them being the symptoms experienced on a daily basis. A study of a cohort of HIV-positive veterans in the United States showed that several of the symptoms they experienced predicted decreased quality of life, survival, and increased hospitalisations [49]. The most prevalent symptoms found in other countries with large cohorts of PLHIV are sleep problems, muscle pain, fatigue, sadness, anxiety, sexual problems, and abdominal pain/distension [50]. SEISIDA studies [51,52] show data in line with these findings, as the most prevalent symptoms in PLHIV in Spain are the same, and the most bothersome are sleep and sexual problems. The general health and symptoms experienced by PLHIV relate to many aspects of the process of living with HIV; the experiences, thoughts and emotions involved. A qualitative study that SEISIDA and the Institute for Global Health (ISGlobal) are conducting to improve the quality of life of PLHIV shows, among other findings, that sleep problems and fatigue are related to social problems prevalent in HIV, such as economic deprivation and stigma. These symptoms are also associated with the emotional distress caused by the worries and fears that PLHIV have to cope with on a daily basis, such as uncertainty about the future or fear of rejection. These or other symptoms are also related to health habits or effects of medication. Symptoms are interconnected and often lead to a "vicious cycle" as they have different possible causes, the causes may determine various symptoms and depending on them, the intervention and self-management of the symptom will be different. So where should we start? It is essential to detect these problems in order to be able to intervene and respond to them. Studies show a very high discrepancy between the symptoms reported by patients and what their doctors thought they were suffering from. The SEISIDA and ISGlobal qualitative study explored the reasons for the lack of detection and management of important symptoms and concerns of PLHIV in routine clinical practice [51]. The difficulty for the patient to define what is wrong or what he/she feels (i.e. to identify it), the lack of knowledge or solutions to the problem and the deficits in the relationship between the health professional and the patient, among other aspects, mean that no response is given to these health-related problems that can damage quality of life [53].

\section{Conclusion:}

The life of an HIV-positive patient brings with it a daily need to take responsibility and self-manage their health process, and this involves making physical, but also psychological and social adjustments that are closely related. Self-management tasks involve managing medical issues, such as taking medication, managing adverse effects or symptoms; managing behaviours, such as lifestyle and habits; and coping with emotional issues associated with HIV.

\section{WHAT ROLE SHOULD THE MEDIA PLAY?}

\section{Alipio Gutiérrez}

The first thing is to observe the maximum scientific rigor. In the same way that medicine is moving towards precision, personalised medicine, we should seek precision journalism. With rigor, with data and scientific evidence. All the more so because now the media, like citizens, also communicate through social networks and there, scientific evidence does not gain value, it is not a plus in any way. Sometimes, on the contrary, the scientific truth about any health issue, and in this case, about HIV infection, has no relevance because anyone can assert their opinion on whatever they want and even if they do not have the truth, if they have a loyal following on social media, they can make that opinion prevail over the scientific reality of the moment. This is why I believe that it is necessary to effectively design specific profiles for the media, scientific societies, patient associations and health administrations in order to know how to "compete" in this new communication scenario.

Secondly, we must fight the social stigma of those affected by HIV. For this, "MASS MEDIA" is the best and most effective tool, together with the school. It has taken decades to put a face to this disease and it is still "hidden" today. What is hidden does not exist and also prevents normalisation. We must commit to the elimination of the social stigma against people affected by HIV that affects their lives.

Thirdly, the media should bring back the visibility that this epidemic had when it was deadly. At the time, it was frequently featured in the media. Now that the disease "does not kill", and has become chronic, it is no longer news. But this makes it all the more paradoxical. I believe that this is a commitment of ours that is highly topical because we are in the "time of chronicity" and it is important that everything related to HIV, from research to the social normalisation of those affected, is 
once again reflected in the different media as a reflection of what is happening in society.

Finally, I am going to say something which, being a journalist myself, may come as a shock: we have to stop being objective about health issues in general. We must be belligerent with scientific evidence, with scientific rigor and eliminate this perverse practice of journalism that, in my opinion, is not sustainable in terms of health. Some media treat health issues like any other issue, wielding an objectivity based on EQUIDISTANCE, offering the same time, the same space in a newspaper, TV or radio programme to those who hold one opinion and those who oppose it. This is NOT VALID in health. It is as if, by virtue of this objectivity/equidistance, we were to propose, for example, offering the same time and space in the media to those who defend the Universal Declaration of Human Rights and those who violate them.

With health issues, and HIV being a clear example, we have to be belligerent and always take the side of scientific evidence.

\section{Conclusion:}

In its relation to HIV disease, the media must remain topical, adhere to scientific objectivity, help to overcome the social stigma of those affected and contribute to the physical and psychological well-being of those affected.

\section{HAVE WE ENDED VERTICAL TRANSMISSION?}

\section{Jose Tomás Ramos}

Vertical transmission (VT) is the predominant mode of HIV-1 transmission in children and is the route of infection for the vast majority of new infections worldwide. In natural history, VT ranges from 15-25\% in the absence of breastfeeding, rising to $40 \%$ in populations where breastfeeding is necessary, such as in low-income countries where the vast majority of infections occur globally [54]. Since the 1994 ACTG 076 trial, in which zidovudine was administered in pregnancy, delivery and to the neonate, documenting $67 \%$ efficacy of antiretroviral therapy (ART) in preventing $V T$, there have been enormous advances in the prevention of VT [16]. Viral load in pregnancy is the most important independent factor associated with VT. In developed countries, the use of combination ART and effective virological suppression to undetectable levels in pregnancy, maintained during delivery, leads to transmission rates of less than 1\% [55]. Prospective follow-up of pregnant women with HIV and their children has been carried out since 2000 in 9 public hospitals in the Community of Madrid, with data from 1,475 mother-child pairs up to December 2018. Overall VT was 1.2\% (95\% Cl: 0.7-1.8\%), currently less than 0.5\%. Moreover, in the few VT cases that have occurred, there were missed opportunities to avoid it [56]. When effective ART is initiated before conception and undetectable viral load is maintained until delivery, vertical transmission may be eliminated, as demonstrated by a study in France in which of 2,651 mothers who initiated ART before conception and remained with viral load <
50 copies/ml close to delivery; there was not a single transmission to the newborn (95\% Cl): 0.1\%) [57].

In low-income countries, where breastfeeding is the main source of nutrients, VT can also be drastically reduced to rates below 2\% with early detection of infection in pregnancy and continuous ART during breastfeeding to be maintained for life (WHO option $\mathrm{B}+$ ), which would prevent infection in new pregnancies. Although progress is quite remarkable, with the number of pregnant women treated with antiretrovirals having doubled in the last decade to $92 \%$, and the number of new infections in children having fallen by more than 70\%, there were still 160,000 new infections in children by VT in 2018 [28].

The goal of VT elimination requires much more than the availability, efficacy and safety of antiretrovirals for universal lifelong treatment in women. A comprehensive approach is needed, including reducing new infections in women of childbearing age and a sequence of maternal and newborn interventions, the removal of which at any point can lead to reduced effectiveness in preventing VT. This chain of prevention includes adequate gestational control with sufficient antenatal care, HIV testing and repeat testing during pregnancy and in low-income countries also during breastfeeding, ART as early as possible for new diagnoses in pregnancy, post-exposure prophylaxis for newborns, and retention in the health system. It is precisely the most vulnerable populations that have the greatest difficulty in complying with all the Available at:s in the epidemiological chain, and in whom prevention failures are most common. These higher-risk groups include migrant populations who are diagnosed or who present late during pregnancy or childbirth, drug users or the growing population of mothers who are themselves infected by $V T$, in whom adherence is a challenge and selection of resistant virus more prevalent.

On the other hand, although current ART is very effective and integrase inhibitors allow for a more rapid decline in viral load during pregnancy, they are not without toxicity. Current WHO guidelines recommend dolutegravir-based regimens, which may be associated with an increased risk of neural tube defects in sub-Saharan populations. Although the benefits far outweigh the potential adverse effects, comprehensive epidemiological surveillance of all antiretrovirals is required to establish safety in the newborn and thus define the most appropriate treatment regimen in each risk situation.

Even with today's great advances, there are still high-risk cases of vertical transmission where, although it is too late to take preventive measures during pregnancy, it is still possible to intervene at birth and in the newborn with immediate combined prophylaxis. Even when there has been intrauterine infection detected by diagnosis in the first $48 \mathrm{~h}$, immediate ART to the newborn could allow us to prevent the spread of the virus, reduce the viral reservoir as much as possible, and perhaps a potential eradication.

\section{Conclusion:}

Elimination of vertical transmission of HIV in low-income countries is feasible. To achieve this, prevention of 
HIV infection in women of childbearing age and early diagnosis to enable early and safe antiretroviral treatment for all infected women is essential.

\section{WHAT HAPPENED TO CHILDREN BORN WITH HIV?}

\section{Marisa Navarro}

HIV infection in paediatrics has undergone a huge change in recent years thanks to the combination of antiretroviral therapy (CART). CART is preventing perinatal transmission while controlling viral replication in infected children.

In Spain, since 2008 there has been a follow-up cohort of HIV-positive children and adolescents from the AIDS Research Network (CoRISpe), which includes patients treated in Paediatric Units (PU) since 1995. CoRISpe is in turn linked to the HIV Biobank of the AIDS Research Network, and is allowing us to learn about the evolution of paediatric infection in our country.

In CoRISpe, 1,344 patients are registered. Most of them were born before universal HIV screening in pregnant women, with $10 \%$ of patients in the cohort dying, mostly prior to cART.

CoRISpe is a cohort of mainly adolescent and young adult patients who survived the early years of the epidemic before cART became available, with $51 \%$ having transferred to Adult Units (AU). New CoRISpe patients are mainly immigrant children born in sub-Saharan Africa and Central and South America, with new HIV infections in children born in Spain being anecdotal.

At the end of 2017, 403 young adults with vertical transmission are being treated in the AUs. These patients have a median age of 25 (ICER 23.6-25.8) and have been followed up in UA after transition for 7.5 years (ICER 5.1-10.5). Of them, 95\% were born in Spain and 56.7\% are women. Clinical stage is $29.6 \%$ A, 40.4\% B, 30\% C. Some 95\% are receiving CART, with $76 \%$ receiving once-daily (OD) regimens and $81 \%$ with HIV viral load <50 copies $/ \mathrm{ml}$ [58]. Immune status is good, with CD4 of 723/mm3 (RIC 500-965) although 33\% have a CD4/ CD8 ratio below 1 [59].

Analysing the accumulated resistance mutations in a group of 133 patients transferred and compared to patients still in PU, a higher percentage of acquired resistance mutations was observed ( $75 \%$ vs $28 \% p=0.006)$, mainly to nucleoside analogues ( $67 \%$ vs $28 \% p<0.0001)$, and to protease inhibitors ( $32 \%$ vs $16 \% p=0.0384)$. In this substudy, despite having good immune status, 74\% have $>500$ TCD4 cells $/ \mathrm{mm}^{3}$. Only $65 \%$ are found with suppressed viral load, reflecting the difficulties in treating these patients with extensive experience with families of drugs, at complex ages (late adolescents) and tired of taking ART [60].

It should also be noted that after transition, some patients have poor adherence to the health care system with failure to take ART, which in some circumstances leads to disease progression and in some cases ( $2 \%$ of the transition cohort) death [58].
In terms of associated comorbidities, we now know the importance of early treatment, which has been shown to prevent multi-organ damage from the first months of infection, as well as irreparable damage to the nervous system in children. HIV-infected children who are now young adults received CART after the first few years of life and thus neurocognitive impairment has been observed, but with good performance in daily life. Some neuroimaging studies have shown alterations in patients with good neurological function [61].

Cardiovascular comorbidity studied in a study of 150 perinatally transmitted HIV-positive 15-year-old adolescents found an increase in carotid intima media compared to matched healthy controls, an indirect marker of cardiovascular risk [62].

Bone comorbidity studied in a series of 98 adolescents aged 16 years showed 15\% with decreased bone mineral density (BMD), although when adjusted for height, the percentage dropped to $4 \%$. The prevalence of BMD decline correlated with CD4 nadir and CD4/CD8 ratio [63].

HCV co-infection, present in $12 \%$ of patients, has been treated with direct-acting drugs, with a cure rate of close to $100 \%$, although $30 \%$ of patients have liver involvement (F3 and F4 fibrosis) [64].

In terms of sexual and reproductive health, women in the transition cohort have had a significant number of pregnancies, more than 60 . In a study of 28 pregnant women, nine of them (32\%) were at high risk of perinatal transmission because of a detectable viral load close to delivery. In this series, there was no transmission of HIV infection in the second generation thanks to the implementation of retention in care strategies and optimisation of ART [65].

Finally, a poorer quality of life as measured by validated SF12 questionnaires is observed compared to non-HIV young people. Thus in 39 young HIV+ verticals (mean age: 23.36 years, $\mathrm{SD}=3.83$ ) and $39 \mathrm{HIV}$ - (mean age: 22.97 years, $\mathrm{SD}=$ 3.80), HIV + patients were found to have lower scores on the physical health subscale than non-HIV $(P=0.001)$ and the general Spanish youth population $(P=0.006)$. HIV+ patients had lower scores on the mental health subscale (MCS) than the general Spanish youth population $(P<0.001)$. Quality of life was better in HIV+ patients undergoing studies and worse for cocaine and cannabis use $(P=0.002)[66]$.

\section{Conclusion:}

Children born with HIV who are now adolescents and young adults are mostly in a controlled HIV status and need to be kept engaged with the health system and cART. The accumulated experience can help the new generations.

\section{WHAT IS THE ECONOMIC COST OF HIV IN SPAIN AT THE MOMENT?}

\section{José Manuel Martínez Sesmero}

The beneficial effect of antiretroviral therapy (ART) on HIV 
infection and the impact on improving patients' quality of life is undoubted. However, its high cost in a resource-constrained environment makes it necessary to manage expenditure well.

A low CD4 cell count at diagnosis is associated with increased morbidity and mortality and higher costs. Patients with CD4 cell counts below 50 cells/microlitre generate a higher non-CART cost, which decreases substantially when CD4s increase above 100 cells/microlitre[31,48,51,66-72].

There are 146,000 people living with HIV in our country $[21,72,73]$ who will require lifelong treatment. The total cost of ART has risen steadily since the inception of highly active ART, with the annual cost of ART being[30] 734,367,344 euros, and it has been estimated that ART accounts for $73 \%$ of the total lifetime health care costs of HIV patients in the US[74] and $87 \%$ in the first year in Spain [75].

The cost classification orders costs according to which agent bears them. Thus, costs would be grouped into costs for the health sector (basically those previously identified as health costs), costs for the patient and his/her family (most of the non-health costs: transport, time, etc.), and costs for other sectors (non-health costs borne by other public entities or by society as a whole, such as productivity costs), indirect costs [76].

\section{Conclusion:}

The cost of ART per patient per year varies significantly depending on the drugs chosen in the treatment regimen. The average annual cost per HIV patient has fallen considerably in recent years as a result of drug patent expiry and ART optimisation.

\section{ECONOMIC BARRIERS TO HIV MANAGEMENT. GENERIC PHARMACEUTICALS}

\section{Inés Suarez García}

Antiretroviral therapy (ART) has substantially increased the life expectancy of patients living with HIV [77,78], moving to considering HIV infection as a chronic disease in patients receiving ART with virological suppression. Adherence to ART is one of the key determinants of its effectiveness [79] and is of crucial importance given that treatment must be maintained throughout the patient's life.

In the wake of the last economic crisis, several regional health administrations and hospitals have imposed measures to reduce the cost of ART, such as setting an annual cost limit per patient or restricting access to some antiretrovirals. These measures have been applied differently in different autonomous communities in Spain and in some hospitals, producing inequities in access to different ART and being significantly associated with the use of ART regimens not recommended in clinical practice guidelines [69].

Generic drugs are drugs that have demonstrated bioequivalence to branded drugs, but cost less because the patent on the original branded drugs has expired[80]. These drugs have proven to be effective and have reduced morbidity and mortality where they have been used [81]. In recent years, some generic antiretroviral (ARV) drugs have begun to be marketed in Spain, with nevirapine, efavirenz (EFV), lamivudine (3TC), tenofovir disoproxil fumarate (TDF), darunavir, ritonavir, and the combinations abacavir/3TC, emtricitabine (FTC)/TDF, and FTC/TDF/EFV currently available. In a context of limited resources for health care, the use of generics would enable a reduction in the cost of ART.

In the European Union, it is acceptable for a drug to be replaced by its generic equivalent if the generic equivalent has the same composition and pharmaceutical form as the original drug and has demonstrated bioequivalence with the original drug through bioavailability studies [80]. However, it is controversial to substitute a fixed-dose co-formulation (FDC) or a complete single-tablet regimen (STR) for its separate components (de-simplification or breaking of combos). The breakdown of complete single-tablet regimens is the main argument against the use of generic ARVs in clinical practice. Currently, the only full fixed-dose combination regimen of generic drugs available in our country is TDF/FTC/EFV; the other STRs used in ART are not currently available in generic formulation unless their components are administered separately [21,82-84].

De-simplification of STRs could lead to considerable financial savings, making it possible to allocate these resources to other health problems. A cost-benefit study using mathematical simulation estimated savings of $\$ 42,500$ per patient and total savings of $\$ 920,000,000$ for the US healthcare system if treatment with Atripla ${ }^{\circledR}$ (STRs including efavirenz, tenofovir and emtricitabine) were replaced by treatment with three separate daily tablets of generic efavirenz, generic lamivudine and tenofovir [85]. In France, another recent study has also shown that replacing ART regimens with generic drugs leads to considerable savings in health expenditure [86].

On the other hand, criticisms of these changes are based on the fact that switching to a higher number of tablets could decrease adherence and therefore the effectiveness of ART, and could favour the emergence of resistance [80]. Arguments in favour of using STRs include the simplification of treatment that would lead to a better quality of life for patients, and the reduced potential for resistance development by reducing the risk of confounding and the non-adherence to single drugs (selective non-adherence) [87]. The use of STRs has been associated with increased adherence[88-90] and a lower risk of hospitalisation $[88,89]$. In this regard, a recent meta-analysis concluded that STRs were associated with better adherence, better virological response and lower cost than multi-drug therapy, but there was no difference in terms of immune response, mortality, adverse events or tolerability $[90,91]$.

However, most of the studies cited to support the greater effectiveness of STRs versus multiple daily tablets have been conducted in the context of simplification strategies, comparing STRs with other antiretroviral treatments that do not have the same composition or are even from different families (e.g. comparing an integrase inhibitor-based STR with a protease inhibitor-based or non-nucleoside-based pre-treatment). 
There are very few studies that have compared the efficacy of STR treatment with the administration of its components (including generic equivalents) separately. Only 7 observational studies on STR de-simplification breakage strategies have been published. Six of them compared the administration of the brand-name drugs Atripla ${ }^{\circledR}$ [92-94], Atripla ${ }^{\circledR}$ and other fixed-dose combinations $[95,96]$ and Triumeq $^{\circledR}[97]$ with their separate components, and all found similar effectiveness. In addition, another study evaluated Triumeq ${ }^{\circledR}$ de-simplification in a single cohort of patients and found no virological failures at 48 weeks [98].

Although there is no conclusive evidence to show that de-simplification of STRs is associated with reduced treatment effectiveness, Spanish ART guidelines recommend the use of STRs $[83,99]$, and most physicians are not in favour of switching from STRs to their generic components separately: in a study in Spain, only 4.1\% of physicians said they would never prescribe generic ARVs, but 53.3\% would not do so if it meant increasing the number of daily pills. As for STR de-simplification, $63.9 \%$ of doctors think it would be associated with worse adherence and 42\% with lower effectiveness [70]. However, in their latest update, European guidelines recommend the use of generic ARVs even if this means not using STRs [100].

\section{Conclusion:}

Generic ARVs have proven to be effective in the treatment of HIV infection and their use could lead to significant cost savings for the National Health System. Their use would imply switching from STRs to the administration of their components separately (de-simplification or breaking of combos), a strategy that is still controversial, which has led to a lack of widespread use of generic ARVs in our country. However, a small number of observational studies have shown similar effectiveness of the use of STRs with respect to their separate components. It would be desirable to create consensus criteria for the use of generic ARVs that include physicians, patients, and health administration.

\section{WHAT IS THE REALITY OF "SLOW PROGRESSOR" PATIENTS?}

\section{Ezequiel Ruiz-Mateos}

Long-term non-progressors are patients who are at one end of the spectrum of HIV infection progression. When we talk about progression, we mean no clinical progression and no immunovirological progression. Thus, they have high CD4+ lymphocyte counts comparable to the non-HIV-infected population and low or undetectable viral loads (VL) in the absence of antiretroviral therapy (cART). This has led to these subjects being considered as a model for the development of immunotherapeutic and vaccine strategies.

Traditionally, these individuals have been classified: A) from an immunological point of view: Long-term non-progressors (LTNP) with CD4+ cells $>500$ cells $/ \mathrm{mm}^{3}$ for more than
10 years in the absence of cART and usually with $V L<5000$ HIV-1 RNA copies/mL ( $5 \%)$. B) from a virological point of view: subjects with low VL $(<2000$ HIV-1 RNA copies/mL, socalled viraemic controllers $(\mathrm{VC}))$ or undetectable levels $(<40$ HIV-1 RNA copies/mL), elite controllers (EC) $(<1 \%)$, for at least one year in the absence of cART.

Current CART aims for undetectability of $V C$, so in most cases VCs and LTNPs with detectable VC have ended up on CART. In relation to ECs, it was observed that it is a heterogeneous phenotype, with approximately 25\% losing VC control and 40\% having decreased CD4+ levels [101]. These findings, together with others in which ECs have been found to have a higher rate of hospitalisation, preferably for cardiovascular disease, than other non-controller subjects [102], have led to reconsideration of controllers as a model of persistent virological remission in the absence of cART or "functional cure". However, these findings are controversial, as in another cohort, the same authors did not observe such differences [103]. Nor have other large cohorts of controllers found a higher prevalence of cardiovascular disease and other non-AIDS events compared to non-controllers [104].

The key to this controversy is the heterogeneity of the controlling phenotype. ECs can be classified into transient controllers (TC), which are those that eventually lose control of the $\mathrm{VC}$, and persistent controllers (PC), which are those that maintain control of the VC indefinitely $[105,106]$. Finding biomarkers that facilitate the discrimination of these two phenotypes is important for two reasons: 1) it allows us to design treatment strategies for TCs as they eventually progress, 2) it allows us to recognise PC as the true model of functional cure. In fact, different studies have shown that PCs have higher levels of HIV-specific T-response [105], associated with lower viral variability and diversity, along with lower levels of viral reservoir $[105,107]$, and in turn, have lower levels of inflammation [105]. Additionally, it has been shown that these two phenotypes also differ in a peculiar proteomic profile associated with less inflammation in PCs compared to TCs, as well as a different metabolomic and lipidomic profile [71]. These results segregate PCs as the true model of persistent virological remission and, on the other hand, differentiate them from subjects who will lose spontaneous control and should therefore be identified as patients who should be offered treatment.

These findings shed light on the current controversy over whether HIV controllers should be treated with CART. Recent studies have shown that cART in controllers has been associated with a decrease in inflammation and immune activation in these subjects [108]. However, most of the subjects included in these studies were $\mathrm{VC}$ with detectable viral load. According to the results discussed above, in the case of a subject who has been infected for more than 30 years, with persistently undetectable CV and CD4+ cell counts above 500 cells $/ \mathrm{mm}^{3}$, the benefit of CART in this scenario would be more than doubtful, contrary to what would occur in the TC subject, where cART and/or complementary immunotherapeutic strategies would allow lowering the levels of inflammation. 
Therefore, these data support PC as the correct model of functional cure to look to when trying to develop immunotherapeutic strategies. It is worth noting that in recent studies, $50 \%$ of the PCs failed to amplify the virus, and in those that did, the variability and diversity of the virus was very low [105]. Dating studies suggest that the evolution of the virus was stalled at a point very close to infection [105]. These findings suggest that perhaps some individuals managed to control the virus from the beginning and to some extent persistently stopped its replication, so that these subjects could be considered "functionally cured" or even some of them may have achieved a "sterilising cure", i.e. they managed to eradicate the virus. Regardless of whether this is the case, this small group of subjects with a persistent LTNP-EC profile constitute a true model of functional cure. Comprehensive analysis of virological, genetic and immunological factors in these subjects will provide important clues on how to achieve viral reservoir reduction and/or elimination and persistent virological remission in the absence of antiretroviral therapy in the general HIV-infected patient population.

\section{Conclusion}

Slow progressors or non-progressors are a peculiar group among HIV-infected people. Subjects with transient immunovirological control would be candidates for antiretroviral therapy and other complementary immunotherapeutic strategies, whilst those with persistent immunovirological control can be considered a model of functional cure or sustained virological remission.

\section{WHAT IS AN HIV CURE AND HOW IS IT DOCUMENTED?}

\section{Javier Martínez Picado}

Combination antiretroviral therapy is the current standard of care for HIV infection. When used daily, antiretroviral therapy effectively controls HIV replication, prevents the development of AIDS, increases life expectancy and reduces the risk of transmission. In 2019, approximately 26 million people had access to antiretroviral therapy, representing 68\% of all infected people (UNAIDS 2020 report) [109].

However, current antiretroviral treatment is not curative, due to viral persistence in cellular and anatomical reservoirs that escape antiviral drugs or the immune system. Consequently, interruption of therapy results in rapid viral rebound in most infected people, necessitating lifelong treatment. Despite the undoubted benefits of antiretroviral treatment, it also has important limitations: (a) Drug toxicities, complex drug interactions (polypharmacy) and persistent immune dysfunction have significant health consequences; (b) Lifelong adherence to treatment is a challenge for many; (c) Resistance to antiretroviral drugs remains a problem, particularly for those who are not fully adherent to treatment; (d) Stigma is still associated with taking antiviral drugs; (e) Operational and logistical challenges related to involved drug distribution in many parts of the world are formidable, and the economic cost of providing antiretroviral treatment to all people living with HIV may be unsustainable in the long term. As the mortality rate among people living with HIV, due to the widespread use of treatment, declines faster than the number of new HIV infections, the prevalence of people living with HIV has grown significantly worldwide. In addition, the increasing number of people suffering at an older age (>60 years) is associated with a number of new challenges, both clinical and immunological. In the absence of an effective prophylactic HIV vaccine, as well as the challenge of treating more than 38 million people with sustained antiretroviral therapy, it is clear that new therapeutic strategies will be required for effective viral control, prevention or a potential cure. Therefore, there remains a critical medical need for research into new strategies to combat HIV, including the urgency of identifying an effective therapeutic intervention to control the virus in the absence of antiretroviral treatment and ultimately cure HIV [110].

In this context, multiple medical strategies are being explored to eradicate the replication-competent HIV reservoir ("cure") or to control viral rebound in the absence of antiretroviral treatment without HIV eradication ("sustained virological remission").

In recent years, we have learned that the viral reservoir is established soon after viral infection. However, early ART limits the size of viral reservoirs, reduces inflammation and immune activation, and reduces viral diversity in both adults and children, without necessarily delaying viral rebound if ART is stopped. Several compounds, called latency reversal agents, are being tested to assess their ability to reactivate latent viruses that comprise the main viral reservoir in subjects on antiretroviral treatment ("Shock \& Kill" strategy). However, it is still difficult to find a balance between their specific efficacy in viral reactivation and their systemic toxicity. Immune therapies capable of facilitating cytotoxic T cell-mediated killing of infected cells, or antibody-mediated antiviral effect, sometimes in combination with latency reactivation agents, are also being explored. And finally, cell and gene therapies are also being investigated [111]. In this context, allogeneic haematopoietic stem cell transplantation for haematological malignancies contributed in 2007 to the first, and until recently only, case of complete eradication of HIV-1, the "Berlin patient", whose donor had a homozygous mutation in the CCR5 co-receptor for HIV that prevents HIV infection of the grafted cells[23]. In early 2019, a second case of HIV remission was announced in a person who has been off antiviral treatment since September 2017, as part of the IciStem project [112] (www.icistem.org), a multi-centre study to guide and investigate the potential for HIV cure in infected people requiring allogeneic stem cell transplantation due to severe haematological pathologies. However, due to its inherent risk, this strategy is neither scalable nor applicable outside the context of severe haematological malignancies and is therefore limited to a small group of HIV-infected individuals. The challenge is to adapt or find viral remission strategies in the absence of antiretroviral treatment that can reach as many people with HIV infection as possible. 
Conclusion:

There is an urgent need to design and implement innovative strategies based on new molecular mechanisms to cure HIV infection by ending viral persistence. The aim is to improve the quality of life of HIV-infected people by reducing dependence on antiviral drugs, treatment burden and stigma.

\section{WHY AREN'T VACCINES ARRIVING?}

\section{Beatriz Mothe}

Despite multiple HIV prevention methods, including the use of antiretrovirals as PrEP, and the efficacy of current ART and its excellent tolerability profile, an estimated 1.7 million people acquired HIV in 2018 and still one third of the 38 million people living with HIV had not accessed ART according to UNAIDS. This is why the development of preventive and therapeutic vaccines for HIV remains one of the most urgent scientific challenges of our time [113].

One of the main difficulties for vaccine development lies in the great diversity of HIV globally. Subtype $C$ infections accounted for $50 \%$ of infections in 2004. Subtypes A, B, D and $\mathrm{G}$ accounted for $12 \%, 10 \%, 3 \%$ and $6 \%$, respectively; and recombinant subtypes $18 \%$. The fact that different HIV subtypes can differ from each other by more than $30 \%$ in their viral genome makes the development of a universal vaccine very complex [114].

Still, in recent years, major advances have been made in the isolation and characterisation of monoclonal antibodies derived from B cells of people with chronic HIV infection against relatively conserved regions of the broadly neutralising HIV envelope glycoprotein antibodies (bNAbs). Some of these bNAbs target CD4 binding site epitopes, the V3 glycan, the V1V2 apex, the interface region of gp120 or the membrane proximal region of gp41, among others. The use of new single B cell culture methods, high-throughput neutralisation screenings and B cell sorting by flow cytometry with envelope antigens have been key to the isolation and generation of new bNAbs [115].

While progress is being made in understanding how bNAbs can be safely induced by a vaccine, several studies of passive infusion of bNAbs alone or in combination in the non-human primate model of infection using chimeric SIVS (SHIV) suggest promising results in terms of safety and protection, which is associated with the levels of neutralisation of the different antibodies [116]. Several Phase $2 b$ clinical trials are already underway led from the HVTN/HPTN vaccine and prevention trials network (Antibody Mediated Protection (AMP) trials HVTN 704/HPTN 085 NCT02716675 and HVTN 703/HPTN 081 NCT02568215) and their results have just been published in 2021, demonstrating that passive infusion of antibodies can prevent the acquisition of infection of those strains sensitive to CRV01.

Of note is the first Phase $2 b / 3$ clinical trial of a new pre- ventive vaccine candidate that builds on the results of the Thai RV144 trial [117], which demonstrated modest (30\%) - and short-lived - efficacy of protection in a Thai population at low risk of HIV acquisition. The new vaccines are based on the inclusion of mosaic immunogens, which, through bioinformatics optimisation, design HIV proteins with a number of sequence variants with the idea of inducing an immune response to a larger number of circulating viral variants. Studies in the NHP model have shown a vaccine efficacy of 60\% associated with induction of large cytotoxic T-lymphocyte-mediated responses and high levels of monoclonal antibodies [118]. The results of the Phase $2 b / 3$ studies are also being developed through the HVTN and results are expected over the next 3 years.

Finally, the complexity of designing new clinical trials of preventive vaccines following the progressive implementation of PrEP as a prevention measure in populations at high risk of acquiring HIV, both in terms of sample size, implementation and ethical issues, should be emphasised.

The development of a therapeutic vaccine aims to achieve control or complete eradication of HIV from the body without the need for ART. This objective must be achieved through a strategy that is equal to (or better than) the ART, both in terms of cost and accessibility, but above all in terms of security, which sets the bar for non-inferiority very high.

One of the main obstacles to the development of a therapeutic vaccine is also the viral diversity, in addition to the viral subtypes, some of the variability is due to immunological adaptation. HIV mutates and escapes relatively easily from the pressure exerted by cytotoxic T lymphocytes (CTLs) mediated by individual HLA molecules. Therapeutic vaccines must therefore be effective in different locations with different circulating viruses and in populations with widely differing genetic backgrounds [119]. To combat such immense diversity, new immunogen designs are based on attempting to re-educate the HIV-specific immune response against those regions of HIV that are highly conserved among the different viral subtypes responsible for generating highly functional HLA-independent cytotoxic responses $[120,121]$ and are currently in clinical phases of development.

Another major obstacle in the field of HIV cure lies in the relative degree of immunodeficiency of people with HIV infection. High levels of chronic inflammation lead to persistent immune depletion that significantly limits the functionality of CTLs and the longevity of vaccine-induced responses. This is why we often see early clinical trials of new vaccine candidates in groups of patients treated in the earliest stages of HIV infection, whose levels of viral escape and immune depletion are lower than after years of chronic infection. With new developments in the field of immunotherapies in oncology and autoimmune diseases, the combination of therapeutic vaccines with immunomodulatory agents of the immune response is expected to be explored.

Finally, the viral reservoir - made up of latently HIV-infected cells that are relatively invisible to the immune system - is a major source of viral rebound once ART is stopped. 
Most likely, neither eradication nor a functional cure of HIV can be achieved without eliminating or achieving very low levels of viral reservoir while inducing a highly functional and long-lasting immune response [122].

\section{Conclusion:}

The enormous viral diversity and the somatic hypermutation required to induce antibodies with broad neutralising capacity make the development of effective preventive vaccines against the different HIV viral strains extremely difficult. Alternatively, promising results in primate models suggest that passive administration of monoclonal antibodies may have high protective efficacy.

\section{HOW FAR SHOULD WE GO WITH RISK BEHAVIOUR PROPHYLAXIS?}

\section{Pep Coll}

We now have proven prevention tools that we must use if we are serious about ending the HIV epidemic. A very important and relatively new tool that is changing the prevention paradigm is PrEP.

Until just over 7 years ago, the main preventive tool available was the condom, which has prevented countless HIV infections, but has not stopped the flow of new infections.

We now know that the combination of two antiretrovirals (tenofovir, disoproxil, fumarate and emtricitabine) can prevent infection in people exposed to HIV, with close to $100 \%$ effectiveness, provided there is correct adherence to the medication. This is the so-called oral PrEP, which has been approved in the National Health System and which was the great unresolved issue in our system. Such is the evidence available on the efficacy of PrEP that its recommendation [123] is included in most clinical guidelines: the first was published by the US Centers for Disease Control and Prevention in 2014. In 2015, the World Health Organisation stated that PrEP should be offered to all populations at higher risk of HIV infection. It points out that PrEP should be a prevention option in addition to condom use, promotion of HIV testing and counselling, treatment as prevention, male circumcision and harm reduction strategies for people who inject drugs.

Other guidelines, such as those of the European AIDS Clinical Society' and GeSIDA [124], also recommend PrEP for those who may be at higher risk of infection [125].

The Spanish Bioethics Committee has come out in favour of the introduction of $\operatorname{PrEP}[126]$, stating that it is ethical to fund it. The Committee sees this as a case similar to others, such as tobacco, noting that "at no point in the tobacco control debate was there the option of limiting or excluding access to health care for those who had irresponsibly put their health at risk by smoking". This means that we cannot deny a person access to a powerful preventive tool because he or she engages in risky behaviours, or rather what we label as such, with all the stigmatising burden that this can entail.

It is important to note that people who seek PrEP do so because they want to protect themselves, and that in general they want a healthier sex life, without the ongoing threat of HIV. Recall that, according to the World Health Organisation, sexual health is not only the absence of disease but also a state of physical, emotional, mental and social well-being in relation to sexuality. And PrEP shows that users can have a more pleasurable sex life.

But there are still voices arguing that PrEP should be used with caution because it will "open the door to promiscuity" and condom use will be abandoned, with all its consequences. It is true that there is concern about a possible increase in the incidence of other STIs due to so-called "risk compensation", i.e. the adoption of higher risk behaviours (non-use of condoms, increased number of sexual partners, etc.). In this regard, it should be noted that while most clinical trials of PrEP have not observed such "risk compensation", there are implementation studies in which an increase in STIs is observed. In any case, we must bear in mind that this increase has been registered in Spain and other countries for years before the implementation of PrEP, so this increase in STIs cannot be attributed to PrEP, or at least not in its entirety. There are other factors that may influence this increase.

What needs to be done is to implement strategies to counteract this potential increase. One such strategy is regular screening for STIs, which allows early detection and treatment of STIs, many of which are asymptomatic, thus helping to break the chain of transmission. In this regard, some studies show through modelling that regular screening can reduce the incidence of STIs. We also know that the presence of STIs increases the risk of HIV infection, which further supports the recommendation for such screening.

It should be emphasised that PrEP is not only about administering the drug, but also includes follow-up of users, which is an excellent opportunity to maintain contact with health services, allowing for STI screening, counselling and sexual health education, detection of other health problems, e.g. drug use.

PrEP is therefore not synonymous with abandoning condom use, which must continue to play an important role, but is a powerful preventive tool as part of a broader, holistic prevention strategy. At this early stage of the implementation of PrEP in our National Health System, it is essential to promote and facilitate access to PrEP for all those at risk of HIV infection. This requires providing adequate information to the population, especially potential beneficiaries, but also awareness raising and training of health professionals on PrEP.

The challenge is to implement and reinforce all proven effective preventive strategies. If we can, we can dramatically reduce HIV infections, as is already being seen where such strategies are being implemented.

\section{Conclusion:}

Pre-exposure prophylaxis (PrEP) with antiretroviral drugs is proving highly effective in HIV prevention. Possible "side effects", such as an increase in Sexually Trans- 
mitted Infections, are not a reason not to recommend it, but to look for strategies to counteract this potential effect.

\section{COULD YOU SUMMARIZE THE CONTRIBUTIONS OF THE MAJOR GROUPS OF ANTIVIRAL AGENTS?}

\section{Esteban Martínez}

There are four major groups of antiviral agents that have been used in the treatment of HIV infection: nucleoside analogues (NAs), protease inhibitors (PIs), non-nucleoside analogues (NANs) and integrase inhibitors. All of them have played a very important role throughout history [83].

ANs were the beginning of treatment for HIV infection. They were first used as monotherapy, then in dual therapy and even triple therapy. However, suppression of viral replication was suboptimal and clinical benefit was limited. Toxicity had a common mechanism of mitochondrial dysfunction with varied clinical manifestations. The vast majority of antiretroviral regimens have included $\mathrm{AN}$. ANs are components of standard antiretroviral treatment.

Pls changed the natural history of HIV infection. Its pharmacokinetics were improved by boosting with low-dose ritonavir and later with cobicistat. Potentiation allowed Pls to have a high genetic barrier so that resistance mutations were not generated, but also gave them a higher risk of interactions. The toxicity of Pls has generally been digestive and metabolic. Because of their potency and genetic barrier, Pls were the forerunners of the less-than-three-drug regimen.

NANs have had better tolerability and less risk of interactions than Pls. In addition, they have a long half-life, which makes them easy to dose. Unlike other groups, the drugs in the NAN group have generally been able to be taken once a day. In addition, their prolonged half-life has meant that suppression of viral replication can be better maintained than with Pls in cases of occasional suboptimal adherence. Therefore, Pls have been used preferentially in first lines of treatment for many years. However, their low genetic barrier is responsible for the emergence of resistance mutations when viral replication is not suppressed. Familial toxicity is hypersensitivity and, in the case of efavirenz, neuropsychological disturbances that may appear late [100].

Integrase inhibitors combine favourable characteristics of both PIs (genetic barrier, potency) and NANs (simplicity, tolerability), but also have a faster virological suppressive effect, better long-term tolerability, and little risk of interactions. These are currently the preferred antiretroviral treatment components. Toxicity includes neuropsychological disturbances, usually mild and transient, and weight gain.

\section{Conclusion:}

Nucleoside analogues are common components of antiretroviral therapy. Protease inhibitors have a high potency and high genetic barrier. Non-nucleoside analogue drugs have a long half-life and simple dosing. Finally, in- tegrase inhibitors have favourable characteristics of both PIs and NANs, but also have a faster virological suppressive effect, better long-term tolerability, and little risk of interactions.

\section{PARENTERAL ANTIRETROVIRAL THERAPY: HOW OFTEN? COULD IT BE ANNUAL?}

\section{Miguel Górgolas}

Parenteral antiretroviral therapy is now, fortunately, a reality. Long-acting parenteral treatment is available with great success for some chronic diseases, such as schizophrenia, or as a method of contraception. There are many reasons that support its suitability for the treatment of chronic infection in people living with HIV. On the basis that the patient should not be injection-phobic, parenteral treatment has, "a priori", a large number of advantages over oral treatment. Firstly, it can be expected to facilitate good adherence or compliance, as it is, in a way, a form of directly observed treatment administered by health personnel. Secondly, the fact of not having to take daily medication allows the patient to "forget" about the infection and live a completely normal life. Thirdly, it is more than likely to lead to a reduction of the stigma that, unfortunately, still exists for many patients who can sometimes be challenged by the simple fact of having to take daily medication.

Currently, the most advanced development consists of a parenteral treatment based on the administration of two drugs, cabotegravir and rilpivirine, which share the appropriate pharmacokinetic characteristics to be co-administered to achieve high antiviral potency, slow release and low metabolic clearance, allowing for administration every 2 months. This type of treatment is called CARLA, an acronym for Cabotegra$v i r+$ Rilpivirine + Long + Acting.

The first study of this combination, the LATTE-2 trial explored the safety and efficacy of the combination as a maintenance treatment, as well as finding the optimal dosage for subsequent phase III trials. Patients without prior antiretroviral treatment received a 20 -week induction treatment with oral $C A B+A B C / 3 T$. Those who achieved an HIV-1 viral load $<50$ $\mathrm{cop} / \mathrm{mL}$ were randomised to one arm of parenteral treatment every 4 weeks, another arm every 8 weeks and another arm continued with oral treatment. The conclusion was that CARLA demonstrated its ability to maintain undetectable viral load when administered every 4 or 8 weeks [22]. Subsequently, a phase III trial (Flair trial) was conducted in ART-naïve patients who received an effective induction course of DTG/ABA/3TC for 20 weeks followed by cabotegravir and oral rilpivirine for 4 weeks, before switching to parenteral treatment. Those patients who agreed to participate in the study were randomised to receive either CARLA every 4 weeks or continue with oral DTG/ABA/3TC. The efficacy of CARLA was similar to conventional oral treatment and local tolerance of the injections was good, being better tolerated in successive administrations throughout the study [127]. Notably, 97\% of patients 
who agreed to participate in the study and received CARLA preferred the intramuscular regimen to the oral regimen they had taken during induction. Only three patients in the CARLA arm had confirmed virological failure with development of resistance mutations against NNRTI and INSTI. All three patients had the same subtype (A1), a baseline mutation in INSTI (L74I) and concentrations of both drugs below the averages of the treated population. The impact of these findings is being investigated, but does not seem likely to change the good results obtained.

Two similar studies, but with previously treated patients with undetectable viral load (Atlas Trial -every 4 weeks- and Atlas 2M Trial -every 8 weeks-), i.e. "switch" studies, have also demonstrated non-inferiority of CARLA to different oral treatment regimens based on PIs, NNRTIs or integrase inhibitors. Similarly, the satisfaction of patients treated with CARLA is very high. The frequency of discomfort at the drug injection site was high in the first few injections, but as in previous trials, tolerance improved over the course of the study. Again, the number of confirmed virological failures in the CARLA group was very low (1\%), so that only three patients had RPV-resistant mutations, some of which were achieved from the start of treatment $[128,129]$.

The Atlas and Flair studies on CARLA have been able to demonstrate that patient adherence has been very high, with up to $98 \%$ of injections being administered within the scheduled 7-day window. In addition, none of the patients who received treatment beyond 7 days had virological failure. Finally, the possibility of a transitional oral treatment was also explored, in case the patient could not receive the intramuscular dosage, and the result has been satisfactory [130]. In addition, the stigma experienced by people living with HIV may be alleviated by the possibility of switching from oral to injectable treatment, particularly when administered as a long-acting treatment such as CARLA [131].

But progress does not stop there, that is only the beginning. Ideally, a treatment should be available that can be administered, or better, self-administered parenterally, e.g. subcutaneously, or via a slow-release reservoir, every three, six or even twelve months. There are three molecules at different stages of development that could be used in this way. A potent capsid inhibitor (GS-6207) with a half-life of more than 24 weeks and activity against virus resistant to other antiretroviral families, which could be administered subcutaneously. This new drug in development has many advantages. Firstly, it has a novel mechanism of action acting on several targets in capsid function; secondly, it could be used in patients previously treated with several families of antiretrovirals and with virus resistant to them; and finally, due to its long half-life it would allow administration possibly every 6 months. Results to date suggest that a single dose (50-450mg) of GS-6207 administered subcutaneously has potent antiviral activity, with a 1.8-2.2 $\log 10$ copy $/ \mathrm{mL}$ reduction in viral load over 10 days. In addition, the drug was safe, with few mild side effects at the injection site, making it a good candidate for further clinical development $[132,133]$.
A new highly potent antiretroviral reverse transcriptase translocation inhibitor (MK-8591) with a half-life of more than 180 days, which could be administered once a year via an implant, is under study. This molecule maintains its activity against viruses with resistance to other reverse transcriptase inhibitors, with mutations such as K65R, M184V or M184I. A single $10 \mathrm{mg}$ dose achieves an average reduction in HIV-1 viral load of $1.6 \log$ in 7 to 10 days [134].

The main challenge for these drugs is to properly assess with which other drugs they should be combined in order to obtain a truly effective ART that can be administered once or twice a year. In this sense, the pharmaceutical industries have a double challenge: on the one hand, to develop the molecule and, on the other hand, to reach agreements with other companies to build an effective combination.

Finally, administration of neutralising antibodies administered subcutaneously or intravenously on a regular basis could be another parenteral treatment option, preliminary studies of which have already begun [135].

\section{Conclusion:}

Parenteral treatment of HIV infection is a reality that will soon materialise. Its efficacy is similar to conventional oral treatment and allows patients to receive the medication every 8 weeks. The combination of cabotegravir and rilpivirine is the most developed so far, but other promising molecules are in development.

\section{REDUCED DRUG SCHEDULES?}

\section{Federico Pulido}

Since 1996, antiretroviral treatment has consisted of a combination of three drugs. The reason for this number was due to the need to achieve sufficient efficacy to suppress viral replication, without giving the option to select for possible viral variants carrying resistance mutations that would lead to treatment failure, thus maintaining suppression indefiniteIy. As a result, immune impairment was reversed, leading to a dramatic decline in the morbidity and mortality associated with HIV infection. With the drugs available at the time, this could only be achieved by combining three drugs, although it is true that not all three-drug combinations are equally effective.

The emergence in later years of more potent antiretroviral drugs with a higher barrier to resistance led to the possibility of using combinations with fewer drugs. This strategy of reducing the number of drugs as long as it does not lead to a loss of efficacy was motivated by the possibility of reducing toxicities (those derived from the drug that is no longer used) and reducing the cost of treatment [136].

Attempts to use a single potent drug with a high barrier to resistance (boosted protease inhibitor) failed to match the antiviral efficacy achieved with the same drugs in triple combinations for maintenance of virological suppression. However, suppression was maintained in a high number of patients and 
the small number of patients whose viral load rebounded did not select for resistance [137].

Two-drug strategies have produced heterogeneous results, depending mainly on the drugs used in the combination and the patient's therapeutic history[138]. We now have evidence from large randomised clinical trials that some two-drug combinations have the same efficacy in controlling viraemia in previously untreated (naïve) patients and/or maintaining virological control in viraemia-suppressed patients as the best available triple-drug regimens $[67,139]$.

These successful two-drug combinations have in common the presence of a drug with a high barrier to resistance (a boosted protease inhibitor) and/or a second-generation integrase inhibitor, with the addition of a reverse transcriptase inhibitor (nucleoside analogue or non-nucleoside analogue) as a second drug [140].

Today, therefore, highly (and equally) effective antiretroviral regimens composed of two or three drugs are available, with the efficacy of the regimen depending not on the number of drugs used, but on which drugs are used in the combination. The discussion on the required number of drugs $[137,138]$ should therefore be ended, in order to focus on the efficacy and tolerability demonstrated by each specific regimen.

\section{Conclusion:}

It is no longer the number, but the type of drugs that determines the effectiveness of antiretroviral treatment. We currently have guidelines with two drugs whose efficacy and tolerance allow them to be used in clinical practice.

\section{WHAT IS THE FUTURE OF IMMUNOTHERAPY?}

\section{Maye Coiras}

The progression of HIV infection is highly dependent on the timing of CART initiation as it conditions the preservation of a functional immune response. In fact, the lymphocytopenia and immune dysregulation associated with HIV infection are responsible for the development of opportunistic infections and various types of HIV-associated tumours. In particular, during antineoplastic treatment of HIV+ patients with different immunotherapies, it has been observed that some may be useful against viral persistence by affecting HIV latency mechanisms and activating a specific antiviral immune response [141].

To address the different immunotherapy strategies that might be useful for the control of HIV infection, we need to consider the central target of infection: CD4+ T cells. Blocking the binding of the virus to the cell by neutralising antibodies is a potential immunological tool to prevent infection. Approximately 20\% of patients untreated for at least 2 years develop broad spectrum neutralising antibodies (bNAbs) that allow cross-neutralisation of different virus types [142]. This is due to the continuous maturation of affinity against conserved and accessible Env epitopes that evolve as a result of immune pressure. $1 \%$ of patients who develop bNAbs are elite control- lers. Among the main functions of bNAbs are virus neutralisation and Fc-dependent antiviral activity, such as antibody-dependent cellular cytotoxicity (ADCC) [143]. Meanwhile, bNAbs such as VRC01, 3BNC117 and 10-1074 have been shown to be safe and well tolerated after intravenous infusion [144-146]. They induce a significant reduction in viraemia and require less continuous administration than CART. However, the protection they induce is not long-lasting and regular infusions are necessary. In addition, combinations of several bNAbs should be administered to improve efficacy and avoid the emergence of resistant variants, and it is necessary to assess in advance whether the patient's viral variants are sensitive to the combination of bNAbs $[147,148]$. On the other hand, bNAbs can be used for the reverse generation of vaccines and the development of alternative gene therapy strategies to vaccination is being considered $[148,149]$.

On the other hand, the mechanisms of infection developed by HIV lead to a state of immunosuppression that hinders an effective immune response. In this sense, the expression of molecules related to immune control such as CTLA-4 or PD-1/ PD-L1 have been described as possibly responsible for this immune dysfunction during infection. In fact, the expression of these molecules increases during chronic infection and PD-1+ cells contain more viral DNA and RNA $[150,151]$. Therefore, immune checkpoint inhibitors (ICPIs) could be useful for boosting an antiviral and antitumour response and have already been used to treat some HIV-related malignancies [152]. Anti-PD-L1 drugs appear to transiently increase CD4 viral transcription, followed by a reduction in plasma viral RNA [141]. Combining pembrolizumab with latency-reversing agents (LRAs) such as bryostatin would increase HIV replication from reservoir cells without activation and proliferation [151].

To improve the visibility of reservoir cells, specific markers need to be identified. CD30 is a marker of latently infected but transcriptionally active cells and could therefore be a therapeutic target for HIV-1 eradication [152]. In fact, treatment with the anti-CD30 antineoplastic drug brentuximab vedotin has been associated with a reduction in plasma viraemia [153]. On the other hand, homeostatic proliferation of the reservoir by cytokines such as IL-7 is one of the main obstacles to HIV1 eradication. IL-7 levels increase during HIV-associated lymphocytopenia and decrease with immune reconstitution, so administration of IL-7 to aviremic patients increases viral load and CD8 activity [141]. IL-15, another proliferative cytokine produced during acute infection, can also induce NK cell stimulation and proliferation of CD8+ T cells for the destruction of latently infected $\mathrm{CD}_{4} \mathrm{~T}$ cells [154].

Finally, tyrosine kinase inhibitors (TKIs) used for the treatment of chronic myeloid leukaemia have been shown to have a potent antiviral effect against HIV by acting on different cell types: they prevent ex vivo CD4 infection by preserving the antiviral innate immune factor SAMHD1; interfere with IL-2- and IL-7-induced CD4 homeostatic proliferation, which may prevent reservoir turnover; and induce enhanced cytotoxic activity by increasing CD56+ and TCR+ cell populations $[68,155,156]$. 


\section{Conclusions}

Immunotherapy should be considered a very important tool for the control of HIV infection. New advances in neutralising antibody therapy and its application to vaccine development are encouraging, although some issues related to stability and efficacy still need to be addressed. On the other hand, immune-enhancing drugs such as immune checkpoint inhibitors could make reservoir cells visible to the immune system and enhance the antiviral effect of cytotoxic cells, as could tyrosine kinase inhibitors. Improving the immune response is therefore essential for a functional cure of HIV by exerting better control of the reservoir.

\section{WHAT IS THE FUTURE OF HIV SPECIALISTS? José Ignacio Bernardino}

With the full implementation of pre-exposure prophylaxis, early diagnosis, prompt treatment initiation and combination prevention strategies, new HIV infections will gradually decline. As has already been demonstrated in other cities such as London, Paris and San Francisco, HIV specialists in HIV units must take the lead in these initiatives together with other health stakeholders and public health officials. An inescapable and achievable goal is to reach zero new HIV infections in Spain.

With the decline in new HIV infections, the need for specialised HIV units may be questioned. The stigma associated with the infection, unfortunately still very present in our society, together with the general lack of knowledge about HIV infection, even among health professionals, will require the continuity of specialised units. We cannot forget that a significant proportion of new infections come from vulnerable populations such as transgender women, injection drug users and illegal immigrants, adolescents at risk of social exclusion who are often excluded from the health system and who receive social and health care in community centres, sexually transmitted disease clinics, drug user centres and specialised HIV units. The maintenance of these centres is essential for the social and health care of these groups.

At present, the life expectancy of HIV-infected people is similar to that of the general population, so the number of people with HIV infection being followed up in the units will be increasing and this translates into a change in care needs. Growing older with HIV infection, the comorbidities associated with this process, and in short, the chronicity of the different pathologies that can converge in a person with HIV infection, requires a multidisciplinary approach that must be coordinated by the HIV infection specialist. This new landscape is a unique opportunity to lead the transformation of the healthcare system from an outdated and hugely expensive acute care model to a more modern day chronic care model. In these models it is essential to place the patient at the centre of care. A model in which the agents involved coordinate and focus their care on the patient, sharing the same information systems with multi- directional and reciprocal communication channels between patient, professionals and administration is a pending issue in many parts of our country. The elimination of the existing fragmentation between levels of care and different health professionals and the growing use of new technologies and the e-health revolution will help to make the system more efficient and encourage self-care with greater co-responsibility and more active patient participation in the management of their health $[157,158]$.

The enormous efforts of scientists in HIV vaccine development and eradication of HIV infection make close collaboration between HIV clinicians and basic science researchers essential.

Specialists in HIV infection together with other health professionals and community agents continue to work tirelessly to achieve zero new HIV infections in Spain, to eliminate the stigma associated with HIV infection and to achieve the not impossible, but still distant, eradication of HIV infection.

\section{Conclusion:}

Specialised HIV units will continue to be indispensable in the coming years. However, there will be a shift from the current, exhausted, acute patient-centred model to a more efficient model focused on chronic patient care. Experts should continue to contribute to maintaining the high standards in HIV research.

\section{WHAT REMAINS TO BE DONE IN HIGH-INCOME COUNTRIES?}

\section{Santiago Moreno}

The treatment currently prescribed for people with HIV infection is close to optimal, both in absolute terms and relative to the treatment of other chronic diseases. HIV infection is among the diseases for which treatment is available with the highest rate of therapeutic efficacy and the least toxic effects and the greatest impact on the health status of the recipient. Antiretroviral treatment has not only enabled people with HIV infection to have a life expectancy similar to that of the non-HIV-infected population, but to do so with a good quality of life without limitations that might result from the disease itself or from the medication.

In the current situation, it is difficult to improve the treatment of the disease. The prospect of long-acting drugs that will soon allow dosing at extended intervals of several weeks or months will certainly be an improvement, but not a dramatic change. Improving antiretroviral treatment is not really the most important issue at hand, nor is it the most pressing. The most immediate ambition is to achieve a cure for those infected and, even more ambitiously, the availability of a vaccine whose administration to those at risk would prevent them from becoming infected. These are clearly two outstanding issues in the fight against HIV in industrialised countries and globally. Their achievement is not on the near horizon and we are therefore faced with more immediate problems still to be solved. 
The reality we live in our society, and that of people living with HIV infection in particular, requires solutions to identified, well-known, unresolved issues. These are issues that have to do with controlling the epidemic in our environment and improving the quality of life of people living with the infection. In industrialised countries, there remains a high risk of HIV transmission among people who engage in risky practices, primarily unprotected sex, but also among injecting drug users who share injecting equipment. Whatever the route, transmission occurs primarily from people who do not know they are infected and are therefore not receiving antiretroviral treatment. Identifying infected persons and administering antiretroviral treatment to achieve control of viral replication could stop transmission, reduce the incidence of new infections and, overall, control the epidemic with all the associated benefits [159]. It is difficult to understand why, having demonstrated the benefits of diagnosing and treating infected persons, the necessary procedures have not been put in place to achieve this goal. At present, most countries, including Spain, rely for diagnosis on the identification of antecedents or risk practices, which has clearly proved to be insufficient.

In order to bring the epidemic under control, it should be noted that the proposed measure of identifying all infected persons as early as possible and treating them, although the most important, is not sufficient. In the meantime, other measures are needed to limit the transmission of the virus. An effective method of prevention has also been described for this. PrEP has shown efficacy in preventing infection in uninfected people who engage in risky practices not only in clinical trials, but also in real life. Recent population-based experience has shown that PrEP administration is associated with a significant decrease in the incidence of HIV infection, regardless of the percentage of patients with an undetectable viral load [160]. In Spain, this measure has been approved.

Improving the quality of life of people with HIV infection, which is another unfinished business, has nothing to do with the quality of life associated with health status. People on antiretroviral treatment are healthy enough to lead normal social, family and working lives. The quality of life they lack is related to the stigma attached to being HIV-positive and the discrimination they face at many levels, creating real social inequalities [161]. Again, it is inexplicable that in "first world" countries, suffering from a chronic illness can become a reason for discrimination. In this case, the way to combat it is more complex, but it is undoubtedly where a society such as ours is most likely to demonstrate the ability to solve problems that are not easy and that affect a large number of people.

\section{Conclusion:}

In neighbouring countries, HIV infection still presents challenges that have not yet been overcome. Beyond the limited room for improvement in antiretroviral therapy or the achievement of desired HIV cures and vaccines, society and people living with HIV infection need action to achieve urgent goals. Control of the epidemic in an environment such as ours can be achieved if measures of known efficacy, such as early diagnosis and treatment of infected persons, are implemented and PrEP is administered to all persons with an indication. In addition, combating the stigma and discrimination still faced by people who are HIV-positive is the second major issue that all first world countries have yet to address.

\section{WHAT REFLECTIONS FROM AN ETHICAL POINT OF VIEW ARE RAISED?}

\section{Diego Gracia}

It is not possible to talk about the ethics of HIV without recalling the heroic years when a clinical AIDS diagnosis meant a death sentence, usually within fourteen months. This was the case for most of the 1980s. In addition to being an acute and deadly disease, its rapid spread led to it being labelled as "epidemic", triggering uncontrolled fear among health professionals and the general population, in some cases to the point of panic. In such a critical situation, conflicts have soared, and so has ethical reflection. It was common to see articles on ethics in large clinical journals, such as the New England Journal of Medicine, Annals of Internal Medicine, JAMA, Lancet or the British Medical Journal, in a previously unknown proportion. In those days it was not uncommon to say that only with the example of AIDS was it possible to explain the main chapters of an entire ethics course. There were many very serious problems related to a key element of clinical activity: diagnosis. Thus, whether or not it was obligatory to ask the patient's permission to carry out the diagnostic test, given that the professional considered himself to be at risk and therefore believed he was entitled to know if the patient was HIV-positive, even against the patient's wishes. Another serious problem was that of data confidentiality, especially in view of the need to protect patients' sexual partners. No less serious were the problems related to treatment: Were health professionals obliged to assist them, or could they raise any objection? The WHO itself had to intervene by reminding professionals that they were obliged to assist, and that the risk was minimal as long as they took the recommended protective measures into account. Another serious problem was the dispersion and distribution of treatments when they became accessible, given their high cost. No less serious were the conflicts that arose with the testing of new antiretroviral drugs in Asian and African countries. And the list could go on.

Today things are very different. HIV infection has gone from being an acute to a chronic disease, from epidemic to endemic, and from being seen as a public health issue to a private hygiene problem. The latter is something that is rarely reflected upon, yet is becoming increasingly important. I will therefore focus my analysis on this point.

Western medicine did not have truly effective therapeutic resources, both medical and surgical, until the 19th century. It was then that experimental pharmacology and pharmacological therapeutics appeared as disciplines, and when surgery began to succeed in its incursion into the three cavities of 
the human body, the abdominal, thoracic and cranial cavities, thanks to the three great novelties introduced in the second half of the century: antisepsis and asepsis, anaesthesia and haemostasis. For the first time in history, the doctor saw himself as being able to cure diseases. Add to this that from the end of the 18th century, as a consequence of enlightened despotism, governments began to turn health into a political objective, which led to the birth of what was first called Sanitary Police and later Sanitary Policy or Public Health.

This revolution was so far-reaching that the strategies developed by physicians from antiquity until the end of the 18 th century were no longer of interest. Given their very limited therapeutic arsenal, classical physicians sought above all to promote the health of the population by means of very simple and elementary procedures for promoting private hygiene, i.e. health education. Based on a Hippocratic treatise entitled On Airs, Waters and Places, the physicians gradually drew up a catalogue of six major chapters for the promotion of private hygiene. This is what was known in the Middle Ages as the catalogue of unnatural sex res non naturals. The six chapters were: environment (what the Hippocratic writing On Airs, Waters and Places referred to), food and drink (cibus et potus), movement and rest (motus et quies), sleep and wakefulness (somnus et vigilia), excretions and secretions (excreta et secreta) and psychic disorders (affectus animi). Prudent management of these six major chapters was the best way to promote health and prevent disease. Especially chronic disease, because chronic disease has a lot to do with unwise lifestyle management. If a person frequently overeats, he or she will almost certainly become overweight, which in turn predisposes him or her to certain chronic diseases, such as type II diabetes.

As hardly anyone remembers this history anymore, it is worth pointing out that this catalogue was fully valid until the end of the 18th century, and that in the last two hundred years that it has been losing importance in the estimation of doctors, given the progress of diagnostic and therapeutic techniques and the no lesser increase in public hygiene, until it has practically disappeared. However, it is still valid in the case of chronic illnesses, as these are most often caused precisely by a disorder of habits, i.e. lifestyle habits.

HIV infection is now a chronic disease, one of the socalled "sexually transmitted diseases" (STDs). These diseases also have a long history, from which we can perhaps learn something. For example, we can learn from the fact that they were called "moral, secret or shameful diseases". Moral diseases were not so much because they were against good morals, but because they were caused by the disorder of what Latin-speakers called mores, customs. They were diseases directly related to lifestyle habits. This is why they were placed, within the catalogue of unnatural sex res non naturals mentioned above, in the chapter entitled excreta et secreta. These were not exclusively medical problems, but primarily social and cultural issues. The paradigmatic example of STDs during the modern centuries was syphilis. It began to be controlled at the beginning of the 20th century with the appearance of the first synthetic chemotherapy drug, salvarsan, and was given the coup de grace in the middle of the same century with the appearance of penicillin. This was so revolutionary that the 1960s witnessed a profound change in social and cultural habits known as the "sexual revolution". The old controls were relaxed, and "repression" was replaced by permissiveness or "sexual freedom". From one extreme to the other... Until 1981, when HIV infection appeared on the horizon. It started out as a very acute and aggressive disease, which medicine had to control, of course, through new therapies. And this it did. The pace of new drugs and their increasing efficacy has dramatically changed the landscape of the disease over the course of a few decades. But medicine is not finished with it. What has been achieved thus far was its transformation from an acute to a chronic disease. It would therefore seem that the time had come to turn to the strategies that are most appropriate and effective in this type of disease: those that have to do with lifestyle and risk practices. It was time to remember the old story of sex res unnatural. By then, however, the old historical references had been lost, and there was a growing conviction that HIV infection was a purely medical, or rather a pharmacological, problem. Instead of acting on risky practices, it was sufficient to protect oneself by using chemical, physical or pharmacological agents.

It is doubtful that this is the only, let alone the most appropriate strategy to control this infection. Some data are alarming to say the least. One of them is the change in leisure practices, shifting from daytime to night-time, in which in order to resist the fatigue of a sleepless night it is necessary to drink alcohol ("binge drinking") and take stimulant drugs, which in turn diminish self-control, disinhibit sexuality and lead to irresponsible practices which, moreover, tend to be practised in groups, thus producing the "herd" effect, in which individual responsibility is diluted within the group dynamic. All this leads to an irresponsible management of the body, consumption, and sexuality. In the latter, from "sexual repression" one moves to "sexual disinhibition", which uses the other person as an object, or as Kant would say, as a pure "means" and not as an "end" in itself. Humans are moral and not merely natural beings, precisely because we have the status of an "end" and not merely a "means" to be used at the whim of others. Sexuality, like food and alcohol, must be managed wisely. Prudence is the capacity for self-control, and it is responsibility in the management of one's actions and life. And it is also health, private health, something that needs to be promoted through education; through education in general, and also through health education. Health professionals are also educators, and in matters such as those we are analysing here, essential educators. The aim of medicine is not only to cure disease, but to promote health and the prudent and responsible management of the body. At a time when we are approaching the ideal of precision medicine or personalised medicine, we cannot forget that there will be no personalised medicine without educating people in the responsible and prudent management of their bodies and sexuality. This is something that the ancient physicians knew very well, and which today's therapeutic potential is unfortunately making us forget. 


\section{Conclusion:}

The enormous effectiveness of therapeutics, both pharmacological and surgical, and the healthcare importance of public health programmes and health policy, is making us forget something that in traditional medicine was the most important objective of the practitioner's action: namely, education and promotion of private hygiene. This is worth remembering at a time when HIV infection is no longer an acute and potentially life-threatening disease, but a chronic disease, where it is essential that patients learn to manage their bodies wisely and responsibly, normalising their behaviour and avoiding risky practices.

\section{FUNDING}

For transparency purposes, we would like to inform you that GSK has contributed to the funding of this publication. Its content reflects the authors' own opinions, criteria, conclusions and/or findings, which may not necessarily coincide with those of GSK. GSK always recommends that its products are used in accordance with the technical data sheet approved by the health authorities.

\section{CONFLICTS OF INTEREST}

The authors declare no conflicts of interest

\section{REFERENCES}

1. Pneumocystis pneumonia--Los Angeles. 1981. MMWR Morbidity and mortality weekly report. 1996;45(34):729-33.

2. Follow-up on Kaposi's sarcoma and Pneumocystis pneumonia. MMWR Morbidity and mortality weekly report. 1981;30(33):40910.

3. Kaposi's sarcoma and Pneumocystis pneumonia among homosexual men--New York City and California. MMWR Morbidity and mortality weekly report. 1981;30(25):305-8.

4. Pneumocystis pneumonia--Los Angeles. MMWR Morbidity and mortality weekly report. 1981;30(21):250-2.

5. Broder S, Gallo RC. A pathogenic retrovirus (HTLV-III) Available at:ed to AIDS. N Engl J Med. 1984;311(20):1292-7. DOI: 10.1056/ nejm 198411153112006

6. Sarngadharan MG, DeVico AL, Bruch L, Schüpbach J, Gallo RC. HTLV-III: the etiologic agent of AIDS. Princess Takamatsu Symp. 1984;15:301-8

7. Popovic M, Sarngadharan MG, Read E, Gallo RC. Detection, isolation, and continuous production of cytopathic retroviruses (HTLV-III) from patients with AIDS and pre-AIDS. Science. 1984;224(4648):497-500. DOI: 10.1126/science.6200935

8. Gallo RC, Salahuddin SZ, Popovic M, Shearer GM, Kaplan M, Haynes $\mathrm{BF}$, et al. Frequent detection and isolation of cytopathic retroviruses (HTLV-III) from patients with AIDS and at risk for AIDS. Science.

\section{4;224(4648):500-3. DOI: 10.1126/science.6200936}

9. Schüpbach J, Popovic M, Gilden RV, Gonda MA, Sarngadharan MG, Gallo RC. Serological analysis of a subgroup of human T-lymphotropic retroviruses (HTLV-III) associated with AIDS. Science. 1984;224(4648):503-5. DOI: 10.1126/science.6200937

10. Sarngadharan MG, Popovic M, Bruch L, Schüpbach J, Gallo RC. Antibodies reactive with human T-lymphotropic retroviruses (HTLV-III) in the serum of patients with AIDS. Science. 1984;224(4648):506-8. DOI: $10.1126 /$ science. 6324345

11. Safai B, Sarngadharan MG, Groopman JE, Arnett $K_{1}$ Popovic M, Sliski $A$, et al. Seroepidemiological studies of human T-lymphotropic retrovirus type III in acquired immunodeficiency syndrome. Lancet. 1984;1(8392):1438-40. DOI: 10.1016/s0140-6736(84)91933-0

12. Montagnier L, Chermann JC, Barré-Sinoussi F, Klatzmann $D$, Wain-Hobson $S$, Alizon $M$, et al. Lymphadenopathy associated virus and its etiological role in AIDS. Princess Takamatsu Symp. 1984;15:319-31.

13. Montagnier L, Gruest J, Chamaret S, Dauguet C, Axler C, Guétard $D$, et al. Adaptation of lymphadenopathy associated virus (LAV) to replication in EBV-transformed B lymphoblastoid cell lines. Science. 1984;225(4657):63-6. DOI: 10.1126/science.6328661

14. Stevenson RW. Magic Johnson Ends His Career, Saying He Has AIDS Infection; . New York Times, Section A, Page 1: BASKETBALL;. 1991;Nov. 8.

15. Fischl MA, Richman DD, Grieco MH, Gottlieb MS, Volberding PA, Laskin $\mathrm{OL}$, et al. The efficacy of azidothymidine (AZT) in the treatment of patients with AIDS and AIDS-related complex. A double-blind, placebo-controlled trial. N Engl J Med. 1987;317(4):18591. DOI: 10.1056/nejm 198707233170401

16. Connor EM, Sperling RS, Gelber R, Kiselev P, Scott G, O'Sullivan MJ, et al. Reduction of maternal-infant transmission of human immunodeficiency virus type 1 with zidovudine treatment. Pediatric AIDS Clinical Trials Group Protocol 076 Study Group. N Engl J Med. 1994;331(18):1173-80. DOI: 10.1056/nejm199411033311801

17. Gulick RM, Mellors JW, Havlir D, Eron JJ, Gonzalez C, McMahon $D$, et al. Treatment with indinavir, zidovudine, and lamivudine in adults with human immunodeficiency virus infection and prior antiretroviral therapy. N Engl J Med. 1997;337(11):734-9. DOI: 10.1056/nejm 199709113371102

18. Saag MS, Holodniy M, Kuritzkes DR, O'Brien WA, Coombs R, Poscher $M E$, et al. HIV viral load markers in clinical practice. Nature Med. 1996;2(6):625-9. DOI: 10.1038/nm0696-625

19. Castilla J, Del Romero J, Hernando V, Marincovich B, Garcia S, Rodriguez C. Effectiveness of highly active antiretroviral therapy in reducing heterosexual transmission of HIV. J Acquir Immune Defic Syndr. 2005;40(1):96-101. DOI: 10.1097/01. qai.0000157389.78374.45

20. Killingley $B$, Pozniak $A$. The first once-daily single-tablet regimen for the treatment of HIV-infected patients. Drugs Today (Barc). 2007;43(7):427-42. DOI: 10.1358/dot.2007.43.7.1086178

21. Gesida. Medicamentos genéricos en el tratamiento antirretroviral. Available at: http://gesida-seimcorg/wp-content/uploads/2019/01/ gesida_16_genericos_cambios_2-2-1pdf. 2018. 
22. Margolis DA, Gonzalez-Garcia J, Stellbrink HJ, Eron JJ, Yazdanpanah $Y$, Podzamczer D, et al. Long-acting intramuscular cabotegravir and rilpivirine in adults with HIV-1 infection (LATTE-2): 96-week results of a randomised, open-label, phase $2 b$, non-inferiority trial. Lancet. 2017;390(10101):1499-510. DOI: 10.1016/s0140-6736(17)319177

23. Hutter G, Nowak D, Mossner M, Ganepola S, Mussig A, Allers K, et al. Long-term control of HIV by CCR5 Delta32/Delta32 stem-cell transplantation. N Eng J Med. 2009;360(7):692-8. DOI: 10.1056/ NEJMoa0802905

24. Cohen MS, Chen YQ, McCauley M, Gamble T, Hosseinipour MC, Kumarasamy N, et al. Prevention of HIV-1 infection with early antiretroviral therapy. N Eng J Med. 2011;365(6):493-505. DOI: 10.1056/ NEJMoa1105243

25. Grant RM, Lama JR, Anderson PL, McMahan V, Liu AY, Vargas L, et al. Preexposure chemoprophylaxis for HIV prevention in men who have sex with men. N Eng J Med. 2010;363(27):2587-99. DOI: 10.1056/NEJMoa1011205

26. Rodger AJ, Cambiano V, Bruun T, Vernazza P, Collins S, van Lunzen J, et al. Sexual Activity Without Condoms and Risk of HIV Transmission in Serodifferent Couples When the HIV-Positive Partner Is Using Suppressive Antiretroviral Therapy. Jama. 2016;316(2):17181. D0I: $10.1001 /$ jama.2016.5148

27. Rodger AJ, Cambiano V, Bruun T, Vernazza P, Collins S, Degen O, et al. Risk of HIV transmission through condomless sex in serodifferent gay couples with the HIV-positive partner taking suppressive antiretroviral therapy (PARTNER): final results of a multicentre, prospective, observational study. Lancet. 2019;393(10189):242838. DOI: 10.1016/s0140-6736(19)30418-0

28. UNAIDS Report. 2019. https://www.unaids.org/sites/default/files/ media_asset/2019-UNAIDS-data_en.pdf:

29. Plan Nacional sobre el Sida D.G. de Salud Pública CeICNdE. Sistema de Información sobre Nuevos Diagnósticos de VIH y Registro Nacional de Casos de Sida. ISCIII. Madrid;. Available at: en: https:// wwwmscbsgobes/ciudadanos/enfLesiones/enfTransmisibles/sida/ vigilancia/doc/InformeVIH_SIDA_2018_21112018pdf. 2018.

30. Dirección General de Salud Pública Cel. Informe de Evaluación Plan Estratégico de Prevención y Control del VIH e ITS 20132016. Available at: en: https://wwwmscbsgobes/ciudadanos/enfLesiones/enfTransmisibles/sida/planesEstrat/informeEvaluacion_ VDweb_12Dicbre18pdf. 2018.

31. Dirección General de Salud Pública CelCNdEldSCI. Estimación del Continuo de Atención del VIH en España, 2016. Madrid: Unidad de vigilancia del VIH y conductas de riesgo. . Available at: en: https:// wwwmscbsgobes/ciudadanos/enfLesiones/enfTransmisibles/sida/ vigilancia/doc/InformeVIH_SIDA_2018_21112018pdf. 2019.

32. UNAIDS. 90-90-90: an ambitious treatment target to help end the ADIS epidemic. Geneva, Switzerland. Availabe at: http://wwwunaidsorg/en/resources/documents/2017/90-90-90 2014.

33. Kelly SL, Wilson DP. HIV Cascade Monitoring and Simple Modeling Reveal Potential for Reductions in HIV Incidence. J Acquir Immune Defic Syndr. 2015;69(3):257-63. DOI: 10.1097/ qai.0000000000000655
34. Making the end of aids real: consensus building around what we mean by "epidemic contro. UNAIDS report. 2017; Available at: https://www.unaids.org/sites/default/files/media_asset/glion_ oct2017_meeting_report_en.pdf DOI:

35. Documento de consenso para el seguimiento de la infección por el VIH en relación con la reproducción, embarazo, parto y profilaxis de la transmisión vertical del niño expuesto. Available at: http:// gesida-seimcorg/wp-content/uploads/2018/05/gesida_VIH_embarazopdf. 2018. DOI:

36. Bosque-Prous $\mathrm{M}$, Brugal MT. [Harm reduction interventions in drug users: current situation and recommendations]. Gaceta sanitaria. 2016;30 Suppl 1:99-105. DOI: 10.1016/j.gaceta.2016.04.020

37. McCormack SM, Noseda V, Molina JM. PrEP in Europe - expectations, opportunities and barriers. J Int AIDS Soc. 2016;19(7(Suppl 6)):21103. DOI: 10.7448/ias.19.7.2110321103

38. McCormack S, Dunn DT, Desai M, Dolling DI, Gafos M, Gilson R, et al. Pre-exposure prophylaxis to prevent the acquisition of HIV-1 infection (PROUD): effectiveness results from the pilot phase of a pragmatic open-label randomised trial. Lancet. 2016;387(10013):53-60. DOI: 10.1016/s0140-6736(15)00056-2

39. Anonimous. New data on male circumcision and HIV prevention: policy and programme implications. WHO/UNAIDS Technical Consultation on male circumcision and HIV Prevention: research implications for policy and programming Montreux,. WHO,. 2007. Available at: $1 \mathrm{https}: / / a p p s . w h o . i n t /$ iris/bitstream/ handle/10665/250574/WHO-HIV-2016.05-spa.pdf;jsessionid=F1200695B013984193A97828C423C513? sequence $=1$

40. Spielberg F, Levine RO, Weaver M. Self-testing for HIV: a new option for HIV prevention? Lancet Infect Dis. 2004;4(10):640-6. DOI: 10.1016/s1473-3099(04)01150-8

41. Brown AE, Mohammed $H_{1}$ Ogaz D, Kirwan PD, Yung M, Nash SG, et al. Fall in new HIV diagnoses among men who have sex with men (MSM) at selected London sexual health clinics since early 2015: testing or treatment or pre-exposure prophylaxis (PrEP)? Euro Surveill. 2017. 2017;22(25). DOI: 10.2807/1560-7917. Es.2017.22.25.30553

42. Delpech V. Elimination of HIV in the United Kingdom. Revista multidisciplinar del Sida 2018;6(14):12. 2018;Available at: http:// www.revistamultidisciplinardelsida.com/download/elimination-ofhiv-in-the-united-kingdom/. DOI:

43. Rodger AJ, Cambiano V, Bruun T, Vernazza P, Collins S, van Lunzen J, et al. Sexual Activity Without Condoms and Risk of HIV Transmission in Serodifferent Couples When the HIV-Positive Partner Is Using Suppressive Antiretroviral Therapy. Jama. 2016;316(2):17181. DOI: $10.1001 /$ jama.2016.5148

44. WHO. Prevalence of HIV among adults aged 15 to 49, 2017. . Available at: https://wwwwhoint/gho/hiv/epidemic_status/prevalence/ en/. 2018

45. World Health Organization. Estrategia mundial del sector de la salud contra las ITS/VIH 2016-2021. Hacia el fin de las ITS. WHO/ RHR/16.09 $\odot$ Available at: https://wwwwhoint/reproductivehealth/ publications/rtis/ghss-stis/es/. 2016.

46. Ayerdi-Aguirrebengoa O, Vera-Garcia M, Puerta-Lopez T, Rapo- 
so-Utrilla M, Rodriguez-Martin C, Del Romero-Guerrero J. To whom is HIV pre-exposure prophylaxis proposed? Enferm Infecc Microbiol Clin. 2017;35(5):299-302. DOI: 10.1016/j.eimc.2016.06.006

47. Centro Nacional de Epidemiología IdSCl, Plan Nacional sobre el Sida-SG de Promoción de la Salud y Epidemiología. Encuesta Hospitalaria de pacientes con infección por el VIH: Resultados 2016. Análisis de la evolución 2001-2016. Available at: https://wwwmscbsgobes/ciudadanos/enfLesiones/enfTransmisibles/sida/vigilancia/InformeEncuestaHospitalaria2016DEFpdf. 2017.

48. Fuster-Ruiz de Apodaca MJ, Laguia A, Safreed-Harmon K, Lazarus $J V$, Cenoz S, Del Amo J. Assessing quality of life in people with HIV in Spain: psychometric testing of the Spanish version of WHOQOL-HIV-BREF. Health Qual Life Outcomes. 2019;17(1):144. DOI: 10.1186/s12955-019-1208-8

49. Edelman EJ, Gordon K, Justice AC. Patient and provider-reported symptoms in the post-cART era. AIDS Behav. 2011;15(4):853-61. DOI: $10.1007 / \mathrm{s} 10461-010-9706-z$

50. Wilson NL, Azuero A, Vance DE, Richman JS, Moneyham LD, Rap-

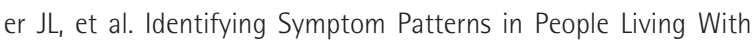
HIV Disease. J Assoc Nurses AIDS Care. 2016;27(2):121-32. DOI: 10.1016/j.jana.2015.11.009

51. Fuster-Ruiz de Apodaca MJ, Laguía A, Safreed-Harmon K, Lazarus JV, Cenoz S, Del Amo J. Assessing quality of life in people with HIV in Spain: psychometric testing of the Spanish version of WHOQOL-HIV-BREF. Health Qual Life Outcomes. 2019;17(1):144. DOI: 10.1186/s12955-019-1208-8

52. Fuster-Ruiz de Apodaca MJ, Sánchez-Vega N, Galindo MJ, Marín-Jimenez I, de Toro J, Orozco-Beltrán D, et al. The Influence of Patient Experience with Healthcare on the Health-Related Quality of Life of People Living with HIV: An Observational Cross-Sectional Survey. Infect Dis Ther. 2019;8(3):369-82. DOI: 10.1007/s40121019-0252-3

53. Lorig KR, Holman H. Self-management education: history, definition, outcomes, and mechanisms. Ann Behav Med. 2003;26(1):1-7. DOI: 10.1207/s15324796abm2601_01

54. Luzuriaga K, Mofenson LM. Challenges in the Elimination of Pediatric HIV-1 Infection. New Engl J Med. 2016;374(8):761-70. DOI: 10.1056/NEJMra1505256

55. Peters $H$, Francis $K$, Sconza R, Horn A, C SP, Tookey PA, et al. UK Mother-to-Child HIV Transmission Rates Continue to Decline: 2012-2014. Clin infect Dis. 2017;64(4):527-8. D0I: 10.1093/cid/ ciw791

56. Prieto LM, Gonzalez-Tome MI, Munoz E, Fernandez-lbieta M, Soto $B$, Del Rosal T, et al. Low rates of mother-to-child transmission of HIV-1 and risk factors for infection in Spain: 2000-2007. Ped Infect Dis J. 2012;31(10):1053-8. D0I: 10.1097/INF.0b013e31826fe968

57. Mandelbrot L, Tubiana R, Le Chenadec J, Dollfus C, Faye A, Pannier $E$, et al. No perinatal HIV-1 transmission from women with effective antiretroviral therapy starting before conception. Clin infect Dis. 2015;61(11):1715-25. DOI: 10.1093/cid/civ578

58. Jiménez De Ory S, González-Tomé MI, Fernández Mcphee C. Situación De Los Pacientes VIH De Transmisión Vertical Transferidos A Unidades De Adultos (CoRISpe-FARO). Poster 112 Congreso GESIDA
2018, Madrid. 2018. DOI:

59. Guillen $\mathrm{S}$, Prieto L, Jimenez de Ory S, Gonzalez-Tome MI, Rojo $P$, Navarro $M L$, et al. Prognostic factors of a lower CD4/CD8 ratio in long term viral suppression HIV infected children. PloS one. 2019;14(8):e0220552. D0I: 10.1371/journal.pone.0220552

60. de Mulder M, Yebra G, Navas A, de Jose MI, Gurbindo MD, Gonzalez-Tome $\mathrm{MI}$, et al. High drug resistance prevalence among vertically HIV-infected patients transferred from pediatric care to adult units in Spain. PloS one. 2012;7(12):e52155. D0I: 10.1371/journal. pone.0052155

61. Ruiz-Saez B, García MM, de Aragon AM, Gil-Correa M, Melero $H$, Malpica NA, et al; Cohorte Nacional de VIH pediátrica de la RED RIS (CoRISpe), Madrid, Spain. Effects of perinatal HIV-infection on the cortical thickness and subcortical gray matter volumes in young adulthood. Medicine (Baltimore). 2021 Apr 16;100(15):e25403. doi: 10.1097/MD.0000000000025403.

62. Sainz T, Alvarez-Fuente M, Navarro ML, Diaz L, Rojo P, Blazquez D, et al. Subclinical atherosclerosis and markers of immune activation in HIV-infected children and adolescents: the CaroVIH Study. J Acquir Immune Defic Syndr. 2014;65(1):42-9. DOI: 10.1097| QAl.0b013e3182a9466a

63. Jimenez B, Sainz T, Diaz L, Mellado MJ, Navarro ML, Rojo P, et al. Low Bone Mineral Density in Vertically HIV-infected Children and Adolescents: Risk Factors and the Role of T-cell Activation and Senescence. Pediatr Infect Dis J. 2017;36(6):578-83. DOI: 10.1097| inf.0000000000001506

64. Carrasco I, Sainz Talia, Frick Marie Antoinette, et al. . Response to Direct Acting Antivirals for hepatitis C treatment in vertically HIV/ HCV co-infected patients. J Viral Hepat. 2020;27(9):955-958. doi: 10.1111/jvh.13308.

65. Prieto LM, Fernandez McPhee C, Rojas P, Mazariegos D, Munoz $E_{1}$ Mellado MJ, et al. Pregnancy outcomes in perinatally HIV-infected young women in Madrid, Spain: 2000-2015. PloS one. 2017;12(8):e0183558. D0I: 10.1371/journal.pone.0183558

66. Cuellar-Flores I, Sainz T, Velo C, Gonzalez-Tome MI, Garcia-Navarro

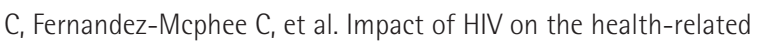
quality of life in youth with perinatally acquired HIV. World J Pediatr. 2019;15(5):492-8. DOI: 10.1007/s12519-019-00281-z

67. Cahn P, Madero JS, Arribas JR, Antinori A, Ortiz R, Clarke AE, et al. Dolutegravir plus lamivudine versus dolutegravir plus tenofovir disoproxil fumarate and emtricitabine in antiretroviral-naive adults with HIV-1 infection (GEMINI-1 and GEMINI-2): week 48 results from two multicentre, double-blind, randomised, non-inferiority, phase 3 trials. Lancet. 2019;393(10167):143-55. DOI: 10.1016/ s0140-6736(18)32462-0

68. Rodriguez-Mora S, Spivak AM, Szaniawski MA, Lopez-Huertas MR, Alcami J, Planelles $V$, et al. Tyrosine Kinase Inhibition: a New Perspective in the Fight against HIV. Current HIV/AIDS reports. 2019;16(5):414-22. DOI: 10.1007/s1 1904-019-00462-5

69. Suarez-Garcia I, Gonzalez J, Berenguer J, Garcia F, Portilla J, Muga $\mathrm{R}$, et al. Reasons for noncompliance with the national guidelines for initial antiretroviral therapy of HIV-infected patients in Spain, 2010-2015. Enferm Infecc Microbiol Clin. 20192019;37(9):580-7. 


\section{DOI: 10.1016/j.eimc.2019.02.007}

70. Suarez-Garcia I, Ruiz-Alguero M, Garcia Yubero C, Moreno C, Belza $M J$, Estebanez $M$, et al. Physicians' opinions on generic antiretroviral drugs and single-tablet regimen de-simplification for the treatment of HIV infection: a multicentre survey in Spain. J Antimicrob Chemother. 2020;75(2):466-72. DOI: 10.1093/jac/dkz439

71. Tarancon-Diez L, Rodriguez-Gallego E, Rull A, Peraire J, Vilades C, Portilla I, et al. Immunometabolism is a key factor for the persistent spontaneous elite control of HIV-1 infection. EBioMedicine. 2019;42:86-96. DOI: 10.1016/j.ebiom.2019.03.004

72. Centro Nacional de Epidemiología - Instituto de Salud Carlos III. Unidad de vigilancia del VIH y conductas de riesgo. Estimación del Continuo de Atención del VIH en España, 2016. Madrid: / Plan Nacional sobre el sida - Dirección General de Salud Pública, Calidad e Innovación; 2019 . Available at: -> https://wwwisciiies/QueHacemos/Servicios/VigilanciaSaludPublicaRENAVE/EnfermedadesTransmisibles/Documents/VIH/INFORMES\%20ESPECIALES/ESTIMACION_ DEL_CONTINUO_DE_ATENCION_DEL_VIH_EN_ESPANA_2019pdf

73. Dirección General de Salud Pública CeICNdEldSCI. Estimación del continuo de atención del VIH en España, 2016. Available at: https:// wwwmscbsgobes/ciudadanos/enfLesiones/enfTransmisibles/sida/ docs/ESTIMACION_DEL_CONTINUO_DE_ATENCION_DEL_VIH_EN_ ESPANApdf.

74. Schackman BR, Gebo KA, Walensky RP, Losina E, Muccio T, Sax PE, et al. The lifetime cost of current human immunodeficiency virus care in the United States. Med Care. 2006;44(11):990-7. DOI: 10.1097/01.mlr.0000228021.89490.2a

75. Ruiz.-Algueró $M$, Suárez-García I, Alvarez-del Arco D, Lázaro $P$, Moreno $S_{1}$ Jarrín I, et al. Uso de recursos sanitarios y costes asociados al tratamiento antirretroviral de primera línea en España en la era de los inhibidores de la integrasa. Available at https://wwwpharmcareespcom/indexphp/PharmaCARE/article/view/500.

76. Documento de consenso de GESIDA/Plan nacional sobre el SIDA respecto al tratamiento antirretroviral en adultos infectados por el virus de la inmunodeficiencia humana. Available at: http:// gesida-seimcorg/wp-content/uploads/2018/01/gesida_TAR_adultos_v3-1pdf.

77. The Antiretroviral Therapy Cohort Collaboration. Life expectancy of individuals on combination antiretroviral therapy in high-income countries: a collaborative analysis of 14 cohort studies. Lancet. 2008;372(9635):293-9. DOI: 10.1016/s0140-6736(08)61113-7

78. Lohse N, Hansen AB, Pedersen G, Kronborg G, Gerstoft J, Sorensen $H T$, et al. Survival of persons with and without HIV infection in Denmark, 1995-2005. Ann Intern Med. 2007;146(2):87-95. DOI: 10.7326/0003-4819-146-2-200701160-00003

79. Wood E, Hogg RS, Yip B, Harrigan PR, O'Shaughnessy MV, Montaner JS. Effect of medication adherence on survival of HIV-infected adults who start highly active antiretroviral therapy when the CD4+ cell count is 0.200 to $0.350 \times 10$ (9) cells/L. Ann Intern Med. 2003;139(10):810-6. DOI: 10.7326/0003-4819-139-10200311180-00008

80. Ramiro MA, Llibre JM. Legal, ethical, and economic implications of breaking down once-daily fixed-dose antiretroviral combinations into their single components for cost reduction. Enferm Infecc Microbiol Clin. 2014;32(9):598-602. D0I: 10.1016/j.eimc.2013.06.008

81. Kumarasamy N, Solomon S, Chaguturu SK, Cecelia AJ, Vallabhaneni S, Flanigan TP, et al. The changing natural history of HIV disease: before and after the introduction of generic antiretroviral therapy in southern India. Clin Infect Dis. 2005;41(10):1525-8. DOI: 10.1086/497267

82. Gesida. Plan nacional sobre el sida respecto al tratamiento antirretroviral en adultos infectados por el virus de la inmunodeficiencia humana. 2019.

83. Gesida. Panel de expertos de GeSIDA y Plan Nacional sobre el Sida. Documento de consenso de GeSIDA/Plan Nacional sobre el Sida respecto al tratamiento antirretroviral en adultos infectados por el virus de la inmunodeficiencia humana (Actualización enero 2019). Available at: http://gesida-seimcorg/wp-content/uploads/2019/01/ gesida_DC_TAR_2019_v_finalpdf.

84. GeSida y Plan Nacional. Panel de expertos de GeSIDA y Plan Nacional sobre el SIDA. Documento de consenso de GeSIDA/Plan Nacional sobre el SIDA respecto al tratamiento antirretroviral en adultos infectados por el virus de la inmunodeficiencia humana. Available at:http://gesida-seimcorg/wp-content/uploads/2019/02/ Guia_Tar_Gesida_Ene_2019pdf.

85. Walensky RP, Sax PE, Nakamura YM, Weinstein MC, Pei PP, Freedberg $K A$, et al. Economic savings versus health losses: the cost-effectiveness of generic antiretroviral therapy in the United States. Ann Intern Med. 2013;158(2):84-92. DOI: 10.7326/0003-4819158-2-201301150-00002

86. Papot E, Landman R, Louni F, Charpentier C, Peytavin G, Certain A, et al. Budget impact of antiretroviral therapy in a French clinic cohort. AIDS. 2017;31(9):1271-9. DOI: 10.1097/qad.0000000000001467

87. Llibre JM, Arribas JR, Domingo P, Gatell JM, Lozano F, Santos JR, et al. Clinical implications of fixed-dose coformulations of antiretrovirals on the outcome of HIV-1 therapy. AIDS. 2011;25(14):1683-90. DOI: 10.1097/QAD.0b013e3283499cd9

88. Cohen CJ, Meyers JL, Davis KL. Association between daily antiretroviral pill burden and treatment adherence, hospitalisation risk, and other healthcare utilisation and costs in a US medicaid population with HIV. BMJ open. 2013;3(8). DOI: 10.1136/bmjopen-2013-003028

89. Sax PE, Meyers JL, Mugavero M, Davis KL. Adherence to antiretroviral treatment and correlation with risk of hospitalization among commercially insured HIV patients in the United States. PloS one. 2012;7(2):e31591. DOI: 10.1371/journal.pone.0031591

90. Ramjan R, Calmy A, Vitoria M, Mills EJ, Hill A, Cooke G, et al. Systematic review and meta-analysis: Patient and programme impact of fixed-dose combination antiretroviral therapy. Trop Med Int Health. 2014;19(5):501-13. DOI: 10.1111/tmi.12297

91. Clay PG, Nag S, Graham CM, Narayanan S. Meta-Analysis of Studies Comparing Single and Multi-Tablet Fixed Dose Combination HIV Treatment Regimens. Medicine. 2015;94(42):e1677. DOI: 10.1097/ md.0000000000001677

92. Llibre JM, de Lazzari E, Molina JM, Gallien S, Gonzalez-Garcia J,

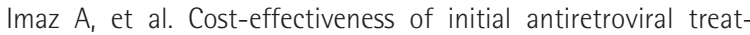


ment administered as single vs. multiple tablet regimens with the same or different components. Enferm Infecc Microbiol Clin. 2018;36(1):16-20. DOI: 10.1016/j.eimc.2016.07.006

93. Engsig FN, Gerstoft J, Helleberg $M$, Nielsen LN, Kronborg G, Mathiesen $L R$, et al. Effectiveness of antiretroviral therapy in individuals who for economic reasons were switched from a once-daily single-tablet regimen to a triple-tablet regimen. J Acquir Immune Defic Syndr. 2014;66(4):407-13. DOI: 10.1097| qai.0000000000000199

94. Beck EJ, Mandalia S, Sangha R, Youle M, Brettle R, Gompels M, et al. Lower healthcare costs associated with the use of a single-pill ARV regimen in the UK, 2004-2008. PloS one. 2012;7(10):e47376. DOI: 10.1371/journal.pone.0047376

95. Homar F, Lozano V, Martinez-Gomez J, Oyaguez I, Pareja A, Payeras $A$, et al. Cost analysis of HIV treatment and drug-related adverse events when fixed-dose combinations of antiretrovirals (FDCs) were stopped, versus continuation with FDCs. Health Econ Rev. 2012;2(1):16. DOI: 10.1186/2191-1991-2-16

96. Rossi MC, Inojosa WO, Battistella G, Carniato A, Farina F, Giobbia $M_{1}$ et al. Desimplification to multi-tablet antiretroviral regimens in human immunodeficiency virus-type 1 infected adults: A cohort study. World J Clin Cases.2019;7(14):1814-24. DOI: 10.12998/wjcc. v7.i14.1814

97. Krentz HB, Campbell S, Lahl M, Gill MJ. De-simplifying single-tablet antiretroviral treatments: uptake, risks and cost savings. HIV Med. 2019;20(3):214-21. D0I: 10.1111/hiv.12701

98. Olalla J, Perez-Stachowski J, Tortajada B, Del Arco A, Marquez E, De la Torre J, et al. Efficacy and safety of the switch of Triumeq(R) to generic (abacavir + lamivudine) + Tivicay(R): data at 24 weeks. BMC Pharmacol Toxicol. 2018;19(1):63. DOI: 10.1186/s40360-0180252-z

99. Gesida. Panel de expertos de GeSIDA y Plan Nacional sobre el Sida. Medicamentos genéricos en el tratamiento antirretroviral. 2019

100. (EACS) EACS. Guidelines Version 10.0 November. Available at: https://wwweacsocietyorg/files/2019_guidelines-100_finalpdf.

101. Leon A, Perez I, Ruiz-Mateos E, Benito JM, Leal M, Lopez-Galin$\operatorname{dez} C_{1}$ et al. Rate and predictors of progression in elite and viremic HIV-1 controllers. AIDS. 2016;30(8):1209-20. DOI: 10.1097/ qad.0000000000001050

102. Crowell TA, Gebo KA, Blankson JN, Korthuis PT, Yehia BR, Rutstein RM, et al. Hospitalization Rates and Reasons Among HIV Elite Controllers and Persons With Medically Controlled HIV Infection. J Infect Dis. 2015;211(11):1692-702. D0I: 10.1093/infdis/jiu809

103. Crowell TA, Ganesan A, Berry SA, Deiss RG, Agan BK, Okulicz JF. Hospitalizations among HIV controllers and persons with medically controlled HIV in the U.S. Military HIV Natural History Study. J Int AIDS Soc. 2016;19(1):20524. DOI: 10.7448/ias.19.1.20524

104. Dominguez-Molina B, Leon A, Rodriguez C, Benito JM, Lopez-Galindez C, Garcia F, et al. Analysis of Non-AIDS-Defining Events in HIV Controllers. Clin Infect Dise. 2016;62(10):1304-9. DOI: 10.1093/cid/ ciw120

105. Pernas M, Tarancon-Diez L, Rodriguez-Gallego E, Gomez J, Prado $J G$, Casado C, et al. Factors Leading to the Loss of Natural Elite Con- trol of HIV-1 Infection. J Virol. 2018;92(5). DOI: 10.1128/jvi.0180517

106. Chereau F, Madec Y, Sabin C, Obel N, Ruiz-Mateos E, Chrysos G, et al. Impact of CD4 and CD8 dynamics and viral rebounds on loss of virological control in HIV controllers. PloS one. 2017;12(4):e0173893. DOI: 10.1371/journal.pone.0173893

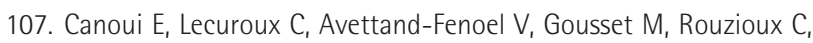
Saez-Cirion A, et al. A Subset of Extreme Human Immunodeficiency Virus (HIV) Controllers is Characterized by a Small HIV Blood Reservoir and a Weak T-Cell Activation Level. Open Forum Infect Dis. 2017;4(2):ofx064. DOI: 10.1093/ofid/ofx064

108. Li JZ, Segal FP, Bosch RJ, Lalama CM, Roberts-Toler C, Delagrev-

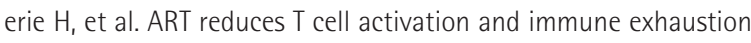
markers in HIV controllers. Clin Infect Dis. 2019. DOI: 10.1093/cid/ ciz442

109. UN Joint Programme on HIV/AIDS (UNAIDS), The Gap Report, 2014, available at: https://www.refworld.org/docid/53f1e1604.html [accessed 11 March 2020] The Gap Report. 2014.

110. Deeks SG, Lewin SR, Ross AL, Ananworanich J, Benkirane M, Cannon $P$, et al. International AIDS Society global scientific strategy: towards an HIV cure 2016. Nature Med. 2016;22(8):839-50. DOI: $10.1038 / n m .4108$

111. Tebas P, Stein D, Tang WW, Frank I, Wang SO, Lee G, et al. Gene editing of CCR5 in autologous CD4 T cells of persons infected with HIV. New Engl J Med. 2014;370(10):901-10. DOI: 10.1056/NEJMoa1300662

112. Gupta RK, Abdul-Jawad S, McCoy LE, Mok HP, Peppa D, Salgado $M$, et al. HIV-1 remission following CCR5Delta32/Delta32 haematopoietic stem-cell transplantation. Nature. 2019;568(7751):244-8. DOI: 10.1038/s41586-019-1027-4

113. Fauci AS, Folkers GK, Marston HD. Ending the global HIV/AIDS pandemic: the critical role of an HIV vaccine. Clin Infect Dis. 2014;59 Suppl 2:S80-4. D0I: 10.1093/cid/ciu420

114. Hemelaar J, Gouws E, Ghys PD, Osmanov S. Global and regional distribution of HIV-1 genetic subtypes and recombinants in 2004. AIDS. 2006;20(16):W13-23. DOI: 10.1097/01.aids.0000247564.73009.bc

115. McCoy LE, Burton DR. Identification and specificity of broadly neutralizing antibodies against HIV. Immunol Rev. 2017;275(1):11-20. DOI: $10.1111 / \mathrm{imr} .12484$

116. Pegu $A$, Borate $B$, Huang $Y$, Pauthner MG, Hessell AJ, Julg $B$, et al. A Meta-analysis of Passive Immunization Studies Shows that Serum-Neutralizing Antibody Titer Associates with Protection against SHIV Challenge. Cell Host Microbe. 2019;26(3):336-46.e3. DOI: 10.1016/j.chom.2019.08.014

117. Rerks-Ngarm S, Pitisuttithum P, Nitayaphan S, Kaewkungwal J, Chiu $J$, Paris $R$, et al. Vaccination with ALVAC and AIDSVAX to prevent HIV-1 infection in Thailand. New Engl J Med. 2009;361(23):220920. DOI: 10.1056/NEJMoa0908492

118. Barouch DH, O'Brien KL, Simmons NL, King SL, Abbink P, Maxfield $L F$, et al. Mosaic HIV-1 vaccines expand the breadth and depth of cellular immune responses in rhesus monkeys. Nature Med. 2010;16(3):319-23. DOI: 10.1038/nm.2089

119. Kawashima Y, Pfafferott $K$, Frater J, Matthews P, Payne R, Addo 
$M_{1}$ et al. Adaptation of HIV-1 to human leukocyte antigen class I. Nature. 2009;458(7238):641-5. DOI: 10.1038/nature07746

120. Mothe B, Llano A, Ibarrondo J, Daniels M, Miranda C, Zamarreno J, et al. Definition of the viral targets of protective HIV-1-specific T cell responses. J Transl Med. 2011;9:208. DOI: 10.1186/1479-58769-208

121. Letourneau S, Im EJ, Mashishi T, Brereton C, Bridgeman $A$, Yang H, et al. Design and pre-clinical evaluation of a universal HIV-1 vaccine. PloS one. 2007;2(10):e984. DOI: 10.1371/journal.pone.0000984

122. Shan L, Deng K, Shroff NS, Durand CM, Rabi SA, Yang HC, et al. Stimulation of HIV-1-specific cytolytic T lymphocytes facilitates elimination of latent viral reservoir after virus reactivation. Immunity. 2012;36(3):491-501. D0I: 10.1016/j.immuni.2012.01.014

123. Organization WH. WHO. WHO expands recommendation on oral pre-exposure prophylaxis of VIH infection (PrEP). 2015;(November). refere. 2015;Available at: at https://www.who.int/hiv/pub/ prep/policy-brief-prep-2015/en/(WHO reference number: WHO/ HIV/2015.48):2.

124. European AIDS Clinical Society (EACS). Guía Clínica Versión 9 Octubre de 2017. Eur AIDS Clin Soc. Available at: - https://wwweacsocietyorg/files/guidlines-90-spanishpdf.

125. Moreno S, Antela A, Garcia F, Del Amo J, Boix V, Coll P, et al. Executive summary: Pre-exposure prophylaxis for prevention of HIV infection in adults in Spain: July 2016. nferm Infecc Microbiol Clin.. 2017;35(6):377-83. DOI: 10.1016/j.eimc.2016.11.016

126. López López MT dMJF, Alonso Bedate C, Bellver Capella V, Cadena

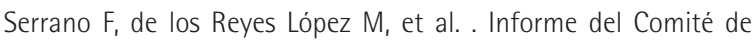
Bioética de España sobre la financiación pública del medicamento Profilaxis preexposición en la prevencion del VIH (PrEP). Available at: http://assetscomitedebioeticaes/files/documentacion/es/Informe_PrEPpdf.

127. Chloe Orkin. Long-acting cabotegravir + rilpivirine for HIV maintenance: flair week 48 results. Available at: http://www.croiconference.org/sessions/long-acting-cabotegravir-rilpivirine-hiv-maintenance-flair-week-48-results.

128. Susan Swindells. Long-acting cabotegravir + rilpivirine for HIV maintenance: flair week 48 results. Available at: http://www. croiconference.org/sessions/long-acting-cabotegravir-rilpivirine-maintenance-therapy-atlas-week-48-results.

129. Efficacy, Safety and Tolerability Study of Long-acting Cabotegravir Plus Long-acting Rilpivirine (CAB LA + RPV LA) in Human-immunodeficiency Virus-1 (HIV-1) Infected Adults. US National Library of Medicine, ClinicalTrialsgov. 2019; Available at: https://clinicaltrials. gov/ct2/show/NCT03299049.

130. Teichner P ea. Patient Adherence to Long-Acting Injectable Cabotegravir + Rilpivirine Through 48 Weeks of Maintenance Therapy in the Phase 3 ATLAS and FLAIR Studies. Open Forum Infect Dis. 2019; Oct; 6(Suppl 2): S20. DOI: 10.1093/ofid/ofz359.043

131. Garris C. Perceptions of and Preferences for Oral or Long-Acting Injectable Antiretroviral Treatment Regimens in the United States and Canada. Open Forum Infect Dis. 2019 Oct; 6(Suppl 2): S866S867. doi: 10.1093/ofid/ofz360.2177

132. Daar Eea. Safety and Antiviral Activity Over 10 Days Following a
Single Dose of Subcutaneous GS-6207, a First-in-Class, Long-Acting HIV Capsid Inhibitor in People Living With HIV. Presented at 10th IAS Conference on HIV Science, 21-24 July. Available at: https://onlinelibrarywileycom/doi/101002/jia225327.

133. Stephen R Y. In Vitro Resistance Profile of GS-6207, a First-in-Class Picomolar HIV Capsid Inhibitor in Clinical Development as a Novel Long-Acting Antiretroviral Agent. Available at: http://wwwnataporg/2019/IAS/IAS_70htm.

134. Glober JA. CROI, Boston, MA. Abst 437LB. Available at: https://wwwiasusaorg/wp-content/uploads/2016/06/24-e1-4pdf.

135. Pegu A. Trispecific antibodies for prevention and treatment of hiv1 infection. Available at:http://www.croiconference.org/sessions/ trispecific-antibodies-prevention-and-treatment-hiv-1-infection. 2018.

136. Pulido $F$, Matarranz $M$, Rodriguez-Rivera $V$, Fiorante $S$, Hernando A. Boosted protease inhibitor monotherapy. What have we learnt after seven years of research? AIDS Rev. 2010;12(3):127-34.

137. Mathis $S$, Khanlari B, Pulido F, Schechter M, Negredo E, Nelson M, et al. Effectiveness of protease inhibitor monotherapy versus combination antiretroviral maintenance therapy: a meta-analysis. PloS one. 2011;6(7):e22003. DOI: 10.1371/journal.pone.0022003

138. Moreno S, Perno CF, Mallon PW, Behrens G, Corbeau P, Routy JP, et al. Two-drug vs. three-drug combinations for HIV-1: Do we have enough data to make the switch? HIV Med. 2019;20 Suppl 4:2-12. DOI: 10.1111/hiv.12716

139. Perez-Molina JA, Pulido F, Di Giambenedetto S, Ribera E, Moreno $\mathrm{S}$, Zamora J, et al. Individual patient data meta-analysis of randomized controlled trials of dual therapy with a boosted PI plus lamivudine for maintenance of virological suppression: GeSIDA study 9717. J Antimicrob Chemother. 2018;73(11):2927-35. DOI: 10.1093/jac/dky299

140. Aboud M, Orkin C, Podzamczer D, Bogner JR, Baker D, Khuong-Josses MA, et al. Efficacy and safety of dolutegravir-rilpivirine for maintenance of virological suppression in adults with HIV-1: 100-week data from the randomised, open-label, phase 3 SWORD-1 and SWORD-2 studies. Lancet HIV. 2019;6(9):e576-e87. DOI: 10.1016/ s2352-3018(19)30149-3

141. Puronen CE, Ford ES, Uldrick TS. Immunotherapy in People With HIV and Cancer. Front Immunol. 2019;10:2060. DOI: 10.3389/fimmu.2019.02060

142. Brady JM, Baltimore D, Balazs AB. Antibody gene transfer with adeno-associated viral vectors as a method for HIV prevention. Immunol Rev. 2017;275(1):324-33. DOI: 10.1111/imr.12478

143. Mouquet H. Antibody B cell responses in HIV-1 infection. Trends Immunol. 2014;35(11):549-61. DOI: 10.1016/j.it.2014.08.007

144. Caskey M, Klein F, Lorenzi JC, Seaman MS, West AP, Jr., Buckley N, et al. Viraemia suppressed in HIV-1-infected humans by broadly neutralizing antibody 3BNC117. Nature. 2015;522(7557):487-91. DOI: 10.1038/nature14411

145. Bar KJ, Sneller MC, Harrison $\sqcup$, Justement JS, Overton ET, Petrone

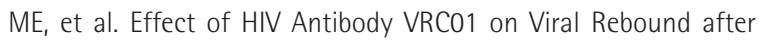
Treatment Interruption. New Engl J Med. 2016;375(21):2037-50. DOI: $10.1056 /$ NEJMoa1608243 
146. Caskey M, Schoofs T, Gruell H, Settler A, Karagounis T, Kreider EF, et al. Antibody 10-1074 suppresses viremia in HIV-1-infected individuals. Nature Med. 2017;23(2):185-91. DOI: 10.1038/nm.4268

147. Mendoza P, Gruell H, Nogueira L, Pai JA, Butler AL, Millard K, et al. Combination therapy with anti-HIV-1 antibodies maintains viral suppression. Nature. 2018;561(7724):479-84. DOI: 10.1038/ s41586-018-0531-2

148. Bar-On Y, Gruell H, Schoofs T, Pai JA, Nogueira L, Butler AL, et al. Safety and antiviral activity of combination HIV-1 broadly neutralizing antibodies in viremic individuals. Nature Med. 2018;24(11):1701-7. DOI: 10.1038/s41591-018-0186-4

149. Rappuoli R, Bottomley MJ, D'Oro U, Finco O, De Gregorio E. Reverse vaccinology 2.0: Human immunology instructs vaccine antigen design. J Exp Med. 2016;213(4):469-81. DOI: 10.1084/jem.20151960

150. Banga R, Procopio FA, Noto A, Pollakis G, Cavassini M, Ohmiti $K$, et al. PD-1(+) and follicular helper T cells are responsible for persistent HIV-1 transcription in treated aviremic individuals. Nature Med. 2016;22(7):754-61. DOI: 10.1038/nm.4113

151. Fromentin R, DaFonseca $S$, Costiniuk CT, El-Far M, Procopio FA, Hecht FM, et al. PD-1 blockade potentiates HIV latency reversal ex vivo in CD4(+) T cells from ART-suppressed individuals. Nat Commun. 2019;10(1):814. DOI: 10.1038/s41467-019-08798-7

152. Brahmer JR, Tykodi SS, Chow LQ, Hwu WJ, Topalian SL, Hwu P, et al. Safety and activity of anti-PD-L1 antibody in patients with advanced cancer. New Engl J Med. 2012;366(26):2455-65. DOI: 10.1056/NEJMoa 1200694

153. Hogan LE, Vasquez J, Hobbs KS, Hanhauser E, Aguilar-Rodriguez $B$, Hussien $R$, et al. Increased HIV-1 transcriptional activity and infectious burden in peripheral blood and gut-associated CD4+ T cells expressing CD30. PLoS pathogens. 2018;14(2):e1006856. DOI: 10.1371/journal.ppat.1006856

154. Garrido C, Abad-Fernandez M, Tuyishime M, Pollara JJ, Ferrari G, Soriano-Sarabia $N_{1}$ et al. Interleukin-15-Stimulated Natural Killer Cells Clear HIV-1-Infected Cells following Latency Reversal Ex Vivo. J Virol. 2018;92(12). DOI: 10.1128/jvi.00235-18

155. Coiras M, Ambrosioni J, Cervantes F, Miro JM, Alcami J. Tyrosine kinase inhibitors: potential use and safety considerations in HIV-1 infection. Expert Opin Drug Saf. 2017;16(5):547-59. DOI: 10.1080/14740338.2017.1313224

156. Bermejo M, Ambrosioni J, Bautista G, Climent N, Mateos E, Rovira

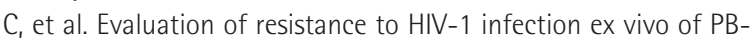
MCs isolated from patients with chronic myeloid leukemia treated with different tyrosine kinase inhibitors. Biochem Pharmacol. 2018;156:248-64. DOI: 10.1016/j.bcp.2018.08.031

157. Lazarus JV, Barton SE, Bernardino Jl. Taking the long-view in a personalised approach to HIV care. Lancet HIV. 2017;4(11):e483-e5. DOI: 10.1016/s2352-3018(17)30182-0

158. SI-health. Descripción del modelo óptimo de atención al paciente VIH. SI-health. Available at: https://viivhealthcarecom/content/dam/cf-viiv/viiv-healthcare/es_ES/documents/Modelo\%20 \%C3\%B3ptimo\%20atenci\%C3\%B3n\%20VIHpdf.

159. Ministerio de Sanidad SSel. Guia de Recomendaciones para el diagnóstico Precoz del VIH en el ámbito sanitario 2014; Available at:
- http://www.mscbs.gob.es/ciudadanos/enflesiones/enfTransmisibles/sida/docs/GUIA_DX_VIH.pdf

160. Sullivan PS ea. The Impact of Pre-exposure Prophylaxis With FC/ TDF on HIV Diagnoses, 2012-2016, United States, 22nd International AIDS Conference, 23-27 July 2018, Amsterdam, the Netherlands. 2018;Available at: http://www.natap.org/2018/IAC/IAC_17. htm(Conference

161. Ministerio de Sanidad CyBS. Plan Nacional sobre el SIDA. Pacto social por la no discriminación y la igualdad de trato asociada al VIH, 2018. Available at: https://wwwomsidaorg/wp-content/uploads/2018/11/PACTO-SOCIAL-2018pdf. 